\title{
Low temperature autoignition of 5-membered ring naphthenes: effects of substitution
}

Aleksandr Fridlyand ${ }^{1}$

S. Scott Goldsborough ${ }^{1, *}$

Mariam Al Rashidi ${ }^{2,3}$

S. Mani Sarathy ${ }^{2}$

Marco Mehl ${ }^{4}$

William J. Pitz ${ }^{4}$

${ }^{1}$ Energy Systems Division, Argonne National Laboratory, Argonne, IL 60439, USA

${ }^{2}$ King Abdullah University of Science and Technology, Clean Combustion Research Center, Thuwal 23955-6900, Saudi Arabia

${ }^{3}$ Department of Chemistry, College of Science, Sharjah University, P. O. Box 27272, Sharjah, UAE

${ }^{4}$ Lawrence Livermore National Laboratory, Livermore, CA, 94551, USA

\section{Corresponding author*:}

\section{S. Scott Goldsborough}

Energy Systems Division

Argonne National Laboratory

9700 S. Cass Avenue

Argonne, IL 60439

USA

Email: scott.goldsborough@anl.gov

Phone: +1-630-252-9375

Fax: +1-630-252-3443 


\section{Abstract}

The development and design of future internal combustion engines requires fundamental understanding and the capability to model the autoignition and pollutant formation behavior of petroleumbased and other fuels. Naphthenes are an important constituent of gasoline, and they can comprise larger portions of unconventionally-derived gasoline. There is a lack of data and validated models for 5-membered ring naphthenes. In this work, the autoignition characteristics of cyclopentane, and two of its substituted analogues, methylcyclopentane, and ethylcyclopentane are investigated using a twin-piston rapid compression machine. Each fuel is studied at engine-representative conditions: 20, 50 bar and 700-980 K, with mixtures containing stoichiometric fuel / oxygen ratios at various extents of dilution with inert gases.

Negative temperature coefficient (NTC) behavior is observed for cyclopentane, though first-stage ignition and associated low temperature heat release behavior are only evident at temperatures below that for the transition to NTC. Pressure is found to have a larger impact on the reactivity than oxygen dilution, with both effects amplified in the NTC region. The cyclopentane experiments in this study are challenged by the sensitivity of this molecule to non-uniform, or mild ignition phenomena within the NTC region. The addition of saturated sidechains in methyl- and ethylcyclopentane significantly increases the reactivity of the molecules, especially at low temperature and NTC conditions. At the highest temperatures though, there is little difference between the three naphthenes. Typical two-stage ignition behavior is observed across a wide range of temperatures for these alkyl cyclopentanes with no mild ignition observed within the NTC region.

A recently developed model for cyclopentane is extended to include reactions for methylcyclopentane, and this is used to simulate the new experiments. The simulation results indicate that low temperature reactivity of cyclopentane is dominated by $\mathrm{HO}_{2}$ elimination of the $\mathrm{RO}_{2}$ species producing cyclopentene, and this inhibits autoignition since it is a very stable molecule. When a methyl group is substituted on the ring, additional $\mathrm{RO}_{2}$ isomerization pathways are available, and these substantially increase the fuel reactivity. $\mathrm{HO}_{2}$ elimination is also important with methylcyclopentane, and this leads to significant production of cyclic olefins 
which can further react to produce diolefins. These findings are consistent with observations that have been made in other experimental apparatuses.

\section{Key Words:}

rapid compression machine, cyclopentane, methylcyclopentane, ethylcyclopentane, chemical kinetic model

\subsection{Introduction}

Naphthenes (or cycloalkanes) are a major constituent of conventional petroleum derived fuels, and they comprise a larger fraction in fuels derived from non-conventional sources such as oil sands and shale [1], liquefied coal [2], and biomass [3-5]. Unlike their linear counterparts, naphthenes are significantly less reactive [6] with increased sooting propensity [7]. While much of the low-temperature chemistry for naphthenes is similar to that of linear alkanes, the cyclic structure of the molecules can hinder internal hydrogen transfer reactions due to the strained, bicyclic transition states that are involved $[8,9]$. This property of naphthenes manifests itself in reduced cycloalkylperoxy radical isomerization rates, leading to decreased reactivity and higher yields of conjugate cycloalkenes [10]. Conjugate cycloalkenes can then react through successive loss of $\mathrm{H}$ atoms, eventually leading to benzene and other soot precursors $[6,8]$. The presence of cycloalkanes in gasoline surrogate mixtures has been shown to act synergistically with aromatics to inhibit negative temperature coefficient (NTC) reactivity [11].

Naphthenes also differ from linear alkanes in how the substitution of hydrocarbon side-chains influences the reactivity of the fuel. In linear structures, methyl or ethyl group substitutions for a hydrogen on the side chain inhibits reactivity. In contrast, substitution of a methyl or ethyl group in naphthenes can significantly enhance the reactivity, where this is attributed in part to the increased availability of low-temperature isomerization pathways for alkylperoxy radicals that are otherwise restricted in the base cycle $[8,12]$.

The differences in molecular structure of naphthenes, and the corresponding influence on chemical kinetic pathways at combustion engine conditions are evidenced by longer ignition delay times observed in rapid compression machines and shock tubes, as well as higher octane ratings in spark-ignition engines (i.e., research octane number (RON) and motor octane number (MON)). For example, Vrankx et al. [13] measured ignition 
times for cyclohexane $(\mathrm{CH})$ in the NTC region that were an order of magnitude longer than n-hexane under similar conditions [14]. Additionally, the antiknock index (AKI), i.e., (RON+MON)/2, of $\mathrm{CH}$ is 80.1 , while that of $n$ hexane is 25.4 , respectively [15]. Furthermore, the AKI of cyclopentane is 94.5 , while that of $n$-pentane is 62.1 . Finally, the AKI of methylcyclohexane is 72.9, and that of ethylcyclohexane is 43.2 [15].

In the past few years, the investigation of naphthene combustion has received greater attention to better understand the governing chemistry and to develop validated chemical kinetic models for use in engine simulations. Although a number of studies have targeted cyclohexane and substituted 6-membered ring naphthenes (i.e., alkyl-cyclohexanes) [13,16-19] far fewer have examined cyclopentane and its substituted analogs. High temperature autoignition behavior of cyclopentane (CPT) and cyclohexane (CH) was investigated in the study of Sirjean et al. [20] using a shock tube, with $\phi=0.5-2,1.9-9 \% \mathrm{O}_{2}$, temperatures of $1230-1840 \mathrm{~K}$, and pressures of 7.4-9.6 bar. They observed that CPT had ignition delays about ten times longer than $\mathrm{CH}$. They developed a chemical kinetic model that was able to capture the observed high-temperature reactivity trends. The model results indicated that the stability of initial cycloalkyl radicals controls reactivity trends at high temperatures, with cyclohexyl radicals leading to earlier formation of $\mathrm{H}$ atoms, which promotes chain branching at their experimental conditions. In a complimentary study, Daley et al. [21] investigated the autoignition of CPT and $\mathrm{CH}$ in a shock tube at higher pressures (11.1-61.8 bar), lower temperatures (847-1379 K), with $\phi=0.25-1$ in air $\left(\sim 21 \% \mathrm{O}_{2}\right)$. Comparison of their experimental results and the model of Sirjean et al. revealed generally poor performance of the model, suggesting that modifications were needed.

Recently, Tian et al. [22] used a shock tube to extend the work of Sirjean et al. [20] and Daley et al. [21] with comparative experiments using methylcyclopentane (MCP). Their experimental conditions were near those of Sirjean et al., using $\phi=0.58-2,3.75-13 \% \mathrm{O}_{2}$, temperatures of $1150-1850 \mathrm{~K}$, and pressures of 1.1-10.1 bar. Tian et al. [22] developed an updated model for CPT and MCP by incorporating new sub-mechanisms into JetSurf2.0 [23] to describe their high temperature chemistry. Simulations with the new model, and that of Sirjean et al. [20] showed reasonably good agreement with the new experimental data. MCP was found to be more reactive 
than CPT due to the weakened $\mathrm{C}-\mathrm{C}$ bonds in the ring adjacent to the methyl group and the unique alkyl radicals that MCP produced, which lead to earlier generation of key radicals that promote chain branching.

Fundamental studies of the low temperature oxidation of 5-membered naphthenes at internal combustion engine conditions are scarce. One of the earliest autoignition investigations of CPT is that from Reitzer and Lamb [24] where they conducted experiments with stoichiometric mixtures of CPT in air using a rapid compression machine $(\mathrm{RCM})$, at compressed pressures of $\mathrm{Pc}=23-33 \mathrm{bar}$, and temperatures of 803-1033 K. They observed longer ignition delay times for CPT compared to iso-octane even though its AKI is lower, and no noticeable NTC behavior.

The most extensive engine-relevant investigations to date with naphthenes were conducted by Yang et al. $[8,9,25,26]$, who studied the oxidative behavior of several cyclic hydrocarbons, including $\mathrm{CH}, \mathrm{MCH}$, and $\mathrm{MCP}$, experimentally using a motored cooperative fuels research (CFR) engine with integrated exhaust speciation, as well as computationally conformational analysis. The compression ratio in the engine was varied to investigate the reactivity of the fuel. Their experimental work showed increased reactivity for $\mathrm{MCH}$ compared to $\mathrm{CH}$ where $\mathrm{CH}$ exhibited stronger NTC behavior than $\mathrm{MCH}$, while MCP showed no NTC behavior. NTC was identified in the engine data via the extents of low temperature heat release (LTHR) and CO production prior to achieving high temperature heat release. For all three molecules, conjugate cycloalkenes were a major product constituent in the engine exhaust. The conformation analysis revealed that the reactivity and emission characteristics for the three molecules investigated are driven by hindered low-temperature isomerization reactions, as discussed earlier.

Guillen et al. [27] recently studied the autoignition of CPT using an Ignition Quality Tester (IQT) at atmospheric pressure, $673-823 \mathrm{~K}$ temperatures, and equivalence ratios of $\phi=0.5-5$, with the oxygen diluted to 13.3\%. At these conditions, the mixture would not readily ignite and only a few data points were collected. No NTC behavior observed at the experimental conditions.

Al Rashidi et al. [10] investigated the oxidation of CPT in a jet-stirred reactor (JSR) at 10 bar, 740-1250 $\mathrm{K}, \phi=0.5-3,0.1 \%$ of fuel in air, and a fixed residence time of $0.7 \mathrm{~s}$. Stable intermediates species were identified 
using gas chromatography and Fourier transform infrared spectroscopy. Interestingly, NTC-like behavior was observed in the reactivity of CPT, but only at $\phi>2$ and temperatures between 850-1000 K. A new chemical kinetic model was developed to interpret the experimental results. The unique NTC-like trend was attributed to the propensity of CPT to generate allyl radicals which tended to recombine into 1,5-hexadiene at their experimental conditions, thereby reducing the reactivity at fuel-rich conditions.

Finally, Al Rashidi et al. [28] followed the aforementioned JSR work with an experimental campaign measuring ignition delay times within an RCM and two shock tube facilities. Lean $(\phi=0.5)$, stoichiometric and rich $(\phi=2)$ mixtures were used, in undiluted blends with air, covering pressures of 20 and 40 bar, and temperatures from 675 to $1316 \mathrm{~K}$. The RCM measurements confirmed NTC behavior of CPT and quantified the influences of $\phi$ and pressure, though no accounting was made of the first-stage ignition, or preliminary heat release characteristics of the fuel. The shock tube measurements were conducted at temperatures greater than the NTC region, while the influences of $\phi$, pressure and temperature were quantified. The model from [10] was tuned to better match the RCM data in this work, where the activation energies of important reaction classes were modified slightly. Reaction path and sensitivity analyses highlighted the importance of concerted elimination reactions of $\mathrm{HO}_{2}$ from cyclopentylperoxy radicals, as well as cyclopentene chemistry in dictating the reactivity of CPT, even at temperatures as low as $700 \mathrm{~K}$.

Compared to 6-membered ring naphthenes and linear alkanes, the autoignition behavior of cyclopentane and corresponding 5-membered ring naphthenes is less well understood, especially at temperatures, pressures, and fuel loading conditions relevant to current and future internal combustion engines. CPT's high octane rating (103 RON) [15], high octane sensitivity (RON-MON = 18) [15], as well as the lack of experimental observations of LTHR, suggest unique NTC behavior. It is critical for chemical kinetic models of transportation fuels to capture such behavior, as well as changes in reactivity due to alterations in molecular structure, e.g., alkyl substitutions on the ring, since low-temperature reactivity of a fuel has strong influence on the load limits and thermal efficiency of advanced internal combustion engines [29]. To address these shortcomings, new experiments are conducted using Argonne National Laboratory's twin-piston RCM (tpRCM), 
measuring the ignition delay times and preliminary heat release rates over a range of conditions for CPT, MCP, and ethylcyclopentane (ECP). The recently developed chemical kinetic model of Al Rashidi et al. $[10,28,30]$ for CPT is extended to include an MCP sub-mechanism, with which we can simulate the experiments and aid the interpretation of the results. Additionally, we use this opportunity to evaluate current predictive capabilities of the model and identify opportunities for improvement.

The manuscript is organized as follows. Section 2 describes the experimental facilities, including recent updates to the system configuration, as well as the data acquisition and post-processing methods. Section 3 provides a description of the chemical kinetic models developed for this work. Section 4 discusses the experimental and simulation results, which is followed by a summary of the study along with conclusions and recommendations for future work in Section 5.

\subsection{Experimental}

\subsection{Rapid Compression Machine}

Argonne's tpRCM is used in this work. A general description of the device's configuration has been presented previously in [31]; this is reviewed while recent modifications and current capabilities are described in detail. The reaction chamber and the two compression cylinders, have a $50.8 \mathrm{~mm}$ inner diameter, while the clearance height is nominally $25.5 \mathrm{~mm}$ at the end of compression. The geometric compression ratio is constant at 12.1:1, while the effective compression ratio, which accounts for heat loss, ranges from 11.2 to 11.8:1, depending on the compressed pressure (Pc) and diluent composition. The stroke for each piston is $155.8 \mathrm{~mm}$. In order to minimize effects of fluid dynamic motion, and provide a quiescent environment in which to study autoignition chemistry, creviced pistons are utilized, which account for, including the tapered channel region, $\sim 14 \%$ of the reaction chamber compressed volume. The shape and dimensions of the pistons are depicted in Fig.

1. 


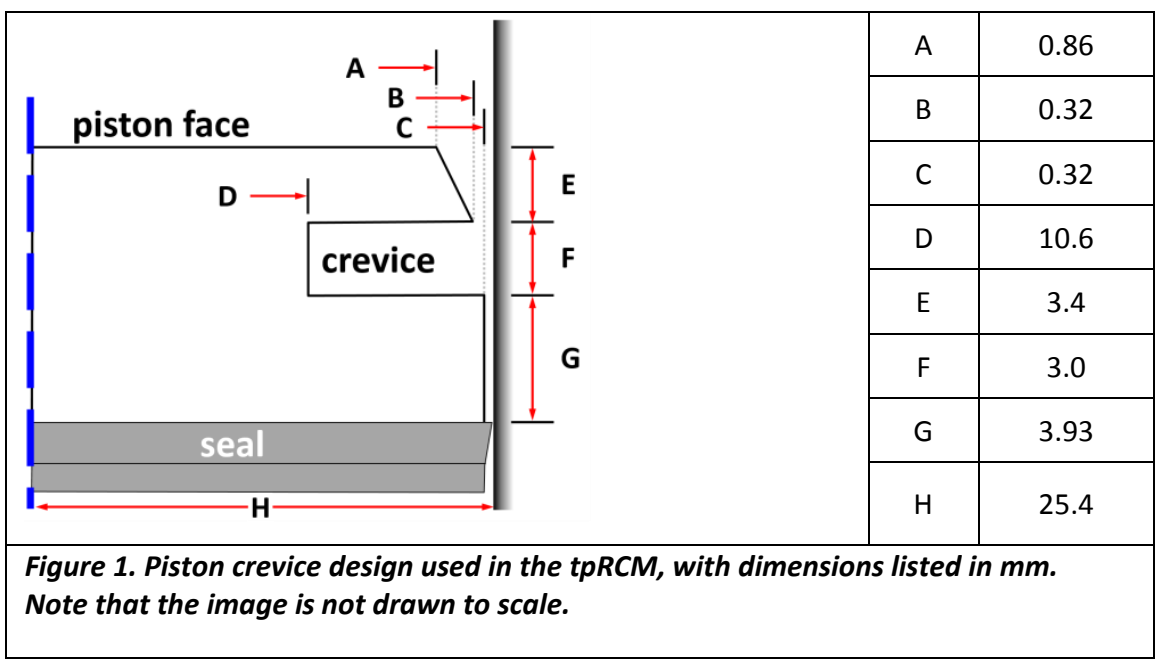

The pistons and reaction chamber components are electropolished and regularly cleaned in a heated, ultrasonic bath of Citranox ${ }^{\circledR}$ weak acid detergent. This ensures minimal risk of surface accumulation and crosscontamination between experiments. In order to reduce the risk of any degassing vapors contaminating the reactive mixture, non-reactive tests are typically performed in the days ahead of the campaign with the reactive mixtures. The ringpacks used for each of the reaction chamber pistons include two Parker o-ring energized Ucup seals, which are oriented in opposite directions to achieve both vacuum and pressure sealing. The o-rings for these are fabricated from Viton, while the U-cup material is virgin Teflon. The o-rings serve to energize the Ucup seals at low pressures and do not provide direct sealing themselves. Located between the two U-cup seals is a $9.3 \mathrm{~mm}$ long, $3.2 \mathrm{~mm}$ thick, glass-reinforced nylon rider ring, purchased from Parker. This ring reduces mechanical wear on the seals. The sealing efficiency of the ringpacks is evaluated daily using test shots of pure nitrogen, and the seals are replaced when the efficiency drops to less than $98 \%$, i.e., when more than $2 \%$ of the gas is lost to blowby. The aft-facing U-cup seal in the ringpack also acts to prevent debris and other contaminants, e.g., hydraulic oil, from entering the reaction chamber.

The tpRCM is pneumatically driven and hydraulically controlled. Hydraulic pistons located centrally on the shafts of the machine serve to lock the shaft in the retracted and compressed positions, and they provide the primary decelerating force at the end of the compression stroke. The hydraulic pistons, which are based on the original ring-groove design of Voinov et al. [32] and later, Affleck and Thomas [33], have been recently reconfigured along with the hydraulic stop to improve the rate of gas compression in order to minimize the extent of reactivity during the last portion of the compression process. Some of the tests (Mixes 1-3, in Table 2) 
use an intermediate, unoptimized configuration that does not sufficiently decelerate the pistons before impacting the hydraulic chamber end plate at $\sim 4 \mathrm{~m} / \mathrm{s}$; these tests exhibit slightly higher shot-to-shot variability, especially when mild ignition occurs, as discussed below. For most of the data set, the compression times are approximately $\mathrm{t}_{\mathrm{comp}}=16.5 \mathrm{~ms}$ at the $\mathrm{Pc}=20$ bar condition, with the last $50 \%$ of the pressure rise occurring in $\mathrm{t}_{50}$ $=1.9 \mathrm{~ms}$. For the $\mathrm{Pc}=50$ bar experiments, $\mathrm{t}_{\mathrm{comp}}=18 \mathrm{~ms}$ due to the increased resistive force on the shaft, with $\mathrm{t}_{50}$ $=2.1 \mathrm{~ms}$.

The tpRCM is designed so that the pistons lock at the compressed position. This is achieved by applying pneumatic and hydraulic forces onto the two shafts. Unlike most hydraulically-controlled RCMs, the hydraulic chambers maintain pressure during actuation via an accumulator, while ports in the grooves are opened to a low-pressure reservoir such that a pressure differential can be created after the pistons are seated. At the highest compressed pressures and lowest dilution levels however, where combustion pressures are highest and the ignition delays are shortest, the hydraulic fluid cannot be transferred from the accumulator quickly enough and this results in the pistons rebounding slightly $(\sim 1-3 \mathrm{~mm})$ after ignition. This is evident in the post-ignition "dip" in some pressure traces, but this introduces negligible uncertainty in the reported ignition delay measurements, as this occurs after most of the heat is already released.

The pressure-time history in the reaction chamber is measured using a flush-mounted Kistler 6045A (0250 bar) transducer coupled with a Kistler Type 5064 charge amplifier. Initial experiments using undiluted, stoichiometric cyclopentane mixtures (Mixes 1-3 below) led to excessive pressure rise rates, e.g., 100 kbar/ms, which damaged the crystal in this transducer. For the remaining experiments, a Kistler 6045A-U20 transducer is utilized with a diaphragm reinforced for knock resistance. Both transducers provide very low thermal shock error $\left(\Delta \mathrm{P}_{\max }< \pm 1 \%\right)$, and are uncoated and uncooled. The signals for all experiments are collected using a National Instruments 9239 data acquisition (DAQ) module, having 24-bit resolution based on a Delta-Sigma analog-to-digital converter, and sampled at $50 \mathrm{kS} / \mathrm{s}$. Low levels of noise are observed in the pressure traces and minimal supplemental filtering is applied, using the Savitzky-Golay algorithm with a second-order polynomial fit 
over an 11 point window (i.e., $0.22 \mathrm{~ms}$ ). This filtered signal is used to compute the ignition delay times as well as the heat release rates, as discussed in detail in the next section.

A wide range of compressed temperatures is reached by using a combination of reaction chamber preheating $\left(T_{i}=22-100^{\circ} \mathrm{C}\right)$ and varying the diluent composition ( $\mathrm{Ar}$ and $\mathrm{N}_{2}$ ). Recent improvements have been made to the heating system in order to achieve low variability along the chamber surface. The reaction chamber, both compression cylinders, and each flange connecting the cylinders to the hydraulic sections are maintained at target temperatures by four dedicated proportional-integral-derivative (PID) control loops. The reaction chamber and compression cylinders are heated by fiberglass-coated heating tapes, and the two flanges are each heated by six cartridge heaters, altogether with a capability of supplying up to $2.1 \mathrm{~kW}$ of electrical power to the machine. No insulation is used to cover external surfaces of the tape or cartridge heaters since this is not needed; however, $6.35 \mathrm{~mm}$ thick, high-density plastic insulators are installed at the mounting points between each compression cylinder flange and the hydraulic chambers in order to eliminate temperature gradients at the retracted piston position. Without these insulators, the hydraulic chambers act as a heat sinks, leading to significant temperature gradients at higher pre-heat temperatures, and potentially buoyancy-induced motion before the start of compression.

The temperature on the outside surface of the reaction chamber and cylinders is periodically monitored using K-type thermocouples at sixteen different positions along the surface. Figure 2 presents representative exterior wall temperatures plotted as a function of position from the axial center of the reaction chamber, over five different heating levels, illustrating the uniformity attained by the upgraded heating system. Interior wall temperatures indicate similar uniformity, with no appreciable thermal gradients around the circumference of the cylinders. Standard deviations on the order of $\pm 0.26 \%$ of the absolute temperature are typical, increasing slightly with the heating load. In Fig. 2 though, it can be seen that the faces of the two pistons have slightly lower temperatures than the walls, since these cannot be directly heated. At the highest heating level, this discrepancy is on the order of $9 \mathrm{~K}$, or less than $3 \%$ absolute. It should be noted that bronze-filled, glassreinforced, polytetrafluoroethylene (PTFE) rider rings were employed in previous tests with the tpRCM in an 
attempt to improve the heat transfer characteristics of the piston-wall interface, and thus elevate the piston face temperature. However, these rings tended to wear significantly and coat the interior surfaces of the compression cylinders, and were thus removed before this experimental campaign was undertaken.

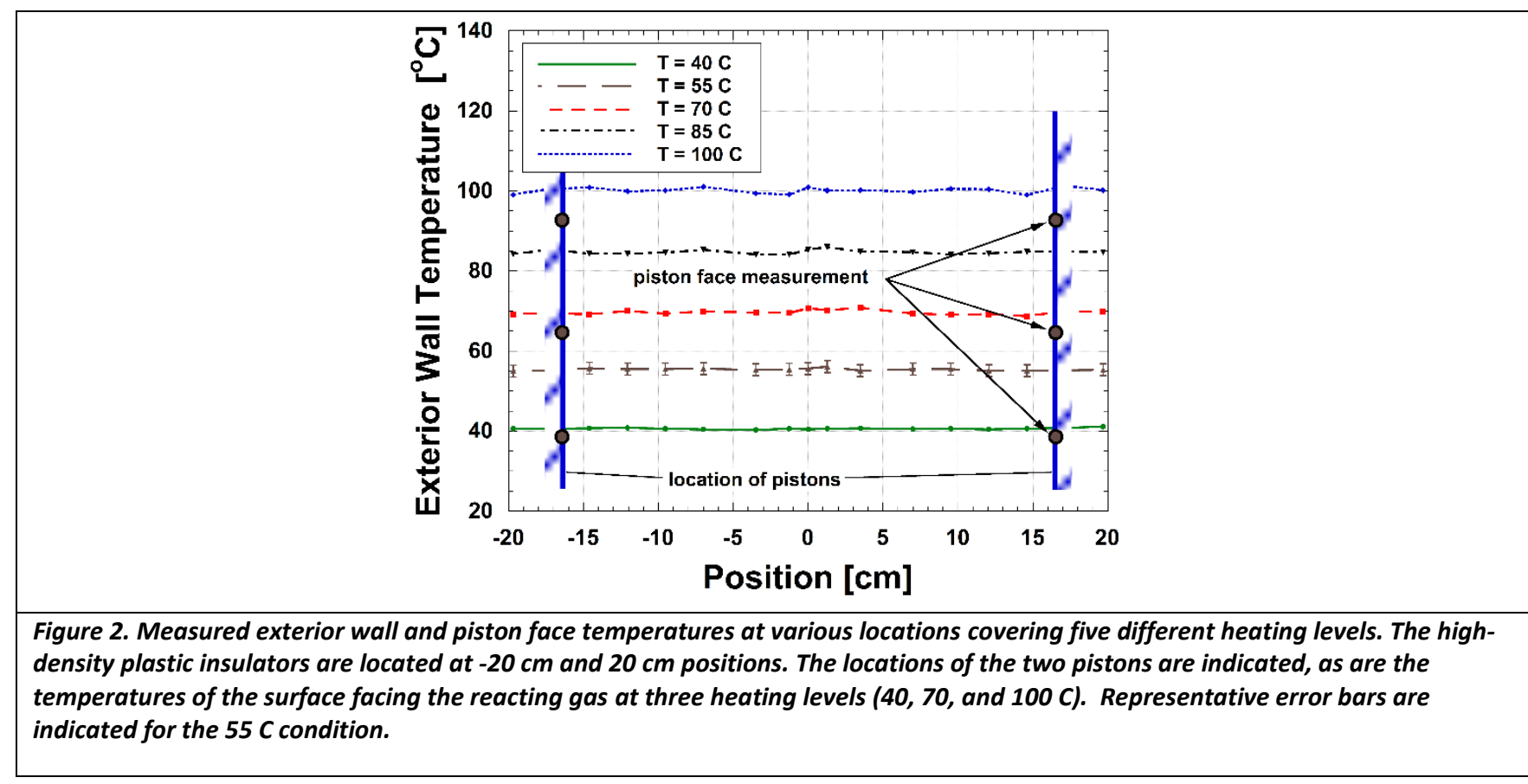

Each test mixture is prepared in a $5.6 \mathrm{~L}$, stainless steel vessel, which is electrically heated to $\sim 70{ }^{\circ} \mathrm{C}$ with

a dedicated PID controller and silicone-coated heating tapes. The gas temperature in the vessel is monitored using an immersed, K-type thermocouple ( $1.5 \mathrm{~mm}$ junction), and the pressure is measured using an MKS Baratron 628F (0-6666 mbar) heated manometer. The mixing tank is initially evacuated and heated to the target temperature overnight. Prior to mixture preparation, it is purged with an inert gas and evacuated to at least 0.1 mbar using an Edwards nXDS6i vacuum pump. Liquid fuel is then injected into the vessel through a septum, and the pressure is allowed to equilibrate. The mass of the syringe is measured prior and post injection using a Denver Instrument Company A-160 scale (0.1 mg precision), which is regularly calibrated. Inert gases, $\mathrm{Ar}$ (99.9997\% purity Airgas) and $\mathrm{N}_{2}$ (99.998\% purity Airgas), are then supplied to the vessel, followed by $\mathrm{O}_{2}$ (99.9997\% purity Airgas). After each gaseous component is added, the temperature and pressure of the mixture is allowed to equilibrate ( $\sim-5 \mathrm{~min})$ before recording the pressure and adding the next component. The test mixture is allowed to mix diffusively for 45 minutes before use. Variations in this wait time have been explored, e.g., 2-3 hrs, with no noticeable change in the ignition delay measurements. Less volatile fuels can require 
longer mixing times however to ensure complete evaporation and homogeneity. All of the fuels used in this study were purchased from Sigma-Aldrich, with purities of greater than $98 \%, 97 \%$, and $98 \%$ for CPT, MCP and $E C P$, respectively. These were not purified further prior to use. The evaporation efficiency with each fuel (based on ideal gas relations) is estimated to be approximately $95 \%$, while the molar composition of the test mixture is calculated based on the mass of the fuel injected and the measured partial pressures of the gaseous components. Associated uncertainties are discussed in the next section.

Prior to firing the tpRCM, the reaction chamber is heated to its target temperature and allowed to equilibrate for 45 minutes. The reaction chamber is then evacuated and purged several times using dry, bottled air (99.998\% purity Airgas). The reaction chamber pressure is monitored for this work using an Omegadyne PX01C1-050AI (0-3446 mbar) pressure transducer. The test mixture is fed to the reaction chamber using a combination of PTFE-lined and stainless-steel tubing, heated to approximately $70^{\circ} \mathrm{C}$ with a dedicated PID controller and a fiberglass coated heating cable. The transfer line is purged and evacuated prior to starting a series of experiments. The test mixture is flowed through a Parker Balston 050-05-BQ, $0.01 \mu \mathrm{m}$ filter in order minimize the risk of introducing particles into the reaction chamber which may initiate non-uniform ignition $[34,35]$. The test mixture is slowly metered into the reaction chamber to the targeted initial pressure, and allowed to equilibrate for at least 5 minutes before firing the tpRCM. It is estimated that, at most, 3-4 minutes should be required for the gas mixture to reach the wall temperature, depending on the thermal diffusivity of the mixture. At each compressed temperature and pressure condition, a minimum of two shots are conducted in order to ensure repeatability. Low scatter, e.g., $< \pm 2 \%$, is typically observed in the ignition delay times, as discussed below.

\subsection{Data Processing and Measurements Uncertainty}

The recorded pressure traces are post-processed to determine the compressed temperatures (Tc), ignition delay times and extents of preliminary heat release. For all of the reactive conditions investigated, a nearly-identical, non-reactive test is conducted in order to ascertain the extent of heat loss experienced during the ignition delay period. For these, the fraction of $\mathrm{O}_{2}$ in the test mixture is replaced by $\mathrm{N}_{2}$ since the heat 
capacity and thermal conductivity are very similar. The non-reactive tests are also used to define the end of compression times $\left(t_{0}\right)$ for each measurement, where the reactive traces are aligned to the non-reactive ones at $75 \%$ of the peak pressure rise. This can be seen in Fig. 3 where representative reactive traces for two compressed conditions are presented, accompanied by the associated non-reactive ones. $t_{0}$, along with both first-stage (cool flame), and main ignition delay times, $\tau_{1}$ and $\tau$, respectively, are highlighted for the $T c=755 \mathrm{~K}$ case.

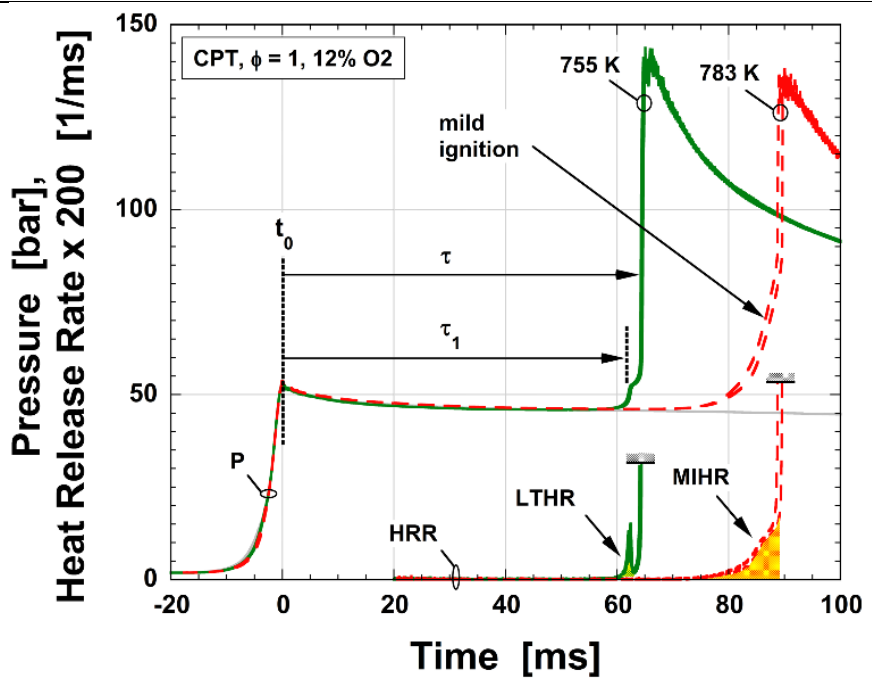

Figure 3. Representative experimental non-reactive and reactive pressure traces and associated heat release rates illustrating raw (gray) and filtered data, definitions for $t_{0}$ and ignition delay times, as well as preliminary heat release. Two reactive traces are shown at each condition. The HRR curves are truncated at times earlier than 20 ms due to noise in the DAQ system and associated analysis at low values of HRRs. Characteristics of mild ignition events are also identified in the Tc $=783 \mathrm{~K}$ trace, and are discussed in the text.

The compressed temperatures are computed using the adiabatic core hypothesis [36],

$$
\int_{T_{i}}^{T_{n r}} \frac{\gamma}{\gamma-1} \frac{d T}{T}=\ln \frac{P_{n r}}{P_{i}}
$$

In this expression, the subscripts ' $\mathrm{i}$ ' and ' $\mathrm{nr}$ ' indicate the initial and instantaneous conditions of the non-reacting mixture, respectively, while $\gamma$ is the ratio of specific heats of the gas mixture. Ideal gas behavior is assumed to be valid over all of the experimental conditions, including pre- and post-compression, and the heat capacity of the gas is taken to be a function of the initial mixture composition and the individual specific heats of the constituents. The specific heats for the three naphthenes are based on polynomial fits to published data [37].

The heat release rates (HRR), and accumulated, or integrated heat release are computed using an energy balance approach as in $[38,39]$, but where the volumetric compression and accompanying heat loss and 
crevice flow processes are empirically incorporated into the analysis via measured non-reacting pressure traces [40]. As shown in the Appendix, this can be expressed as,

$$
H R R=\frac{\gamma}{\gamma-1} \frac{d V}{d t}\left[P-P_{n r}\right]+\frac{V}{\gamma-1}\left[\frac{d P}{d t}-\left.\frac{d P}{d t}\right|_{n r}\right]-\frac{P V}{(\gamma-1)^{2}}\left[\frac{d \gamma}{d t}-\left.\frac{d \gamma}{d t}\right|_{n r}\right]
$$

The calculations are performed on respective reactive and non-reactive filtered signals where the heat capacity of the reacting mixture for this calculation is estimated based on the degree of reaction, with an assumed blend of reactants and (complete) products. The extent of low temperature heat release (LTHR) is taken as the integrated heat release from $t_{0}$ through the peak HRR at first-stage ignition $\left(\tau_{1}\right)$, up to the inflection point in HRR just before the onset of main ignition. The heat release analysis is also useful in identifying instances of mild, or non-uniform ignition [40], where these exhibit a slowly evolving pressure rise indicative of a deflagrative combustion front, which can consume a significant fraction of the fuel's chemical energy (e.g., 40\%) before transition to rapid pressure rise typical of homogeneous (e.g., end gas) autoignition. Mild ignition heat release (MIHR), as depicted in Fig. 3, is taken as the integrated heat release from $t_{0}$ to the transition to rapid autoignition. For the heat release calculations presented in this work, all of the parameters are normalized by the lower heating value (LHV) of the mixture, e.g., $(\mathrm{J} / \mathrm{mol} / \mathrm{ms}) /(\mathrm{J} / \mathrm{mol})$.

Uncertainties associated with RCM experiments can be difficult to accurately quantify and are the subject of ongoing discussion in the community [41]. Most often, the compressed conditions (Tc and Pc) are evaluated as they are in this study, using the adiabatic core hypothesis [36]. Recently, Weber et al. [41] performed an uncertainty propagation analysis for typical RCM experiments in order to estimate the uncertainty in the computed compressed temperatures due to instrumentation imprecision and procedural uncertainties associated with mixture preparation. Recognizing that their estimates are relevant only if the adiabatic core assumption is valid, estimated uncertainties using linear propagation of uncertainty and Monte Carlo simulations were found to be less than $0.7 \%$. They determined that the magnitude of the initial reaction chamber pressure, as well as the uncertainty in thermocouple measurements, had the largest impacts on uncertainty in the compressed temperatures. 
Argonne's tpRCM measurement instruments are regularly calibrated, creviced pistons are utilized, and ignition delay times are typically taken within 1-150 ms in order to ensure that the adiabatic core assumption is valid over a wide range of conditions. Reduced order modeling for this configuration has indicated that the adiabatic core monotonically decays during the test period as the boundary layer diffusively grows, where for $\tau<$ $100 \mathrm{~ms}$, the majority of the mixture is still within the adiabatic core. Assuming that the adiabatic core hypothesis holds for the tests conducted in this study, the uncertainty in compressed temperatures are estimated using the same linear propagation method utilized by Weber et al. [41].

The sources of uncertainty considered here are the initial pressure, compressed pressure, initial temperature, and composition. For the pressures, the maximum manufacturer-specified uncertainties are considered, which are $\pm 3 \%$ for $\mathrm{P}_{\mathrm{i}}$ and $\pm 1 \%$ for $\mathrm{Pc}$, though these could be reduced through more rigorous calibration. For the initial temperatures, the maximum deviation from the mean of the outer surface of the reaction chamber, accounting for the thermocouple uncertainty, is utilized, where this did not exceed $\pm 0.4 \%$ of the absolute temperature. For composition, the largest source of uncertainty is the mole fraction of fuel in the test mixture. It is estimated that this uncertainty is approximately $5 \%$. Combining these components using the linear propagation approach [41], the estimated uncertainties in compressed temperatures are $\sim 0.5 \%$ at Pc $=50$ bar, and $\sim 1 \%$ at Pc $=20$ bar. Using a more conservative estimate of $10 \%$ uncertainty in the fuel mole fraction leads to a maximum uncertainty in the compressed temperature of approximately $\pm 1.5 \%$. No probability distributions for the uncertain components are assumed, and the estimates represent the likely maximum deviation due to imprecision in the experimental apparatus. Any random errors manifest themselves as scatter in the reported values of ignition delay (typically $\pm 2 \%$, with most below $\pm 4 \%$ (excluding mild ignition events)) and compressed pressure measurements $( \pm 0.3 \%)$. A value of $\pm 0.4 \mathrm{~ms}$ is used for each $\tau$ measurement to account for mis-alignment of the non-reacting traces with the reacting ones, though there is no accounting for sampling limitations of the DAQ card which could slightly shift the time of peak pressure rise rate.

As noted in the previous section, recent improvements to the reaction chamber heating system have reduced the wall temperature variations to a standard deviation of $0.12 \%$ absolute at near ambient conditions 
(due primarily to electrical noise), monotonically increasing to $0.23 \%$ at $100{ }^{\circ} \mathrm{C}$. As seen in Fig. 2 , calibration tests of the new heating system indicate that the piston face temperature can be lower than the wall temperature by as much as $2.5 \%$ when heated to $100^{\circ} \mathrm{C}$, and near $0.7 \%$ when the reaction chamber is heated to $40^{\circ} \mathrm{C}$. Recent computational fluid dynamics (CFD) simulations of Neuman and Allen [42] demonstrated that with pistons that are cooler than the reaction chamber walls by $6 \%$, measured ignition delay time deviations of $\sim 5 \%$ can result, though they found no impact on the derived Tc. Since the maximum temperature difference in the current work is significantly less than in their study, subsequent errors in measured $\tau$ are expected to be smaller than the $\pm 5 \%$ reported in [42]. Other systematic uncertainties are difficult to identify, but procedural modifications are continually investigated to eliminate them.

Errors in the heat release rate calculations can also be difficult to estimate, with the biggest sources of error due to the use of a single-zone formulation, and the application of the adiabatic core hypothesis. During exothermic processes there can be heat loss that is greater than experienced with non-reacting mixtures. Furthermore, as the pressure rises in the reaction chamber, gas can be forced into the piston crevice volume. This latter, multi-dimensional effect has been documented through CFD simulations [43], and reduced order modeling [44]. Error bars are included in the presentation of LTHR trends as rough estimates, but a rigorous evaluation of these are the subject of future work.

\subsection{Chemical Kinetic Modeling}

Chemical kinetic models (available as Supplementary Material and at https://cloudflame.kaust.edu.sa [45-47]) are developed and utilized in this work to help interpret the experimental measurements. Simulations are conducted using the homogeneous reactor model approach where the piston compression process and postcompression heat loss are empirically taken into account via volume trajectories deduced from experimental pressure histories measured using non-reacting mixtures, as described in $[36,48]$. The volume histories at each condition are provided as supplementary material. It should be noted that this simple physical model of the experiment cannot account for flow into the crevices and other dead volumes due to preliminary heat release, 
e.g., LTHR, and this is a source of discrepancy between the simulation results and the experimental measurements [43].

\subsection{Cyclopentane Kinetic Model}

The detailed cyclopentane kinetic model developed by Al Rashidi et al. [28,30], with updates from [10], is employed in this study. Briefly, the model comprises low- and high-temperature reactions for CPT pyrolysis and oxidation. Rate coefficients of elementary reactions are taken from the literature when available, such as those of unimolecular decomposition [49] and $\mathrm{H}$-abstraction by $\mathrm{OH}$ [50], or estimated using analogies. Due to the importance of low-temperature chain branching in controlling fuel reactivity as well as the uniqueness of cycloalkane oxidation chemistry [8], the pressure- and temperature-dependent kinetics of all reactions lying on the potential energy surface of cyclopentyl $+\mathrm{O}_{2}$ are determined computationally by Al Rashidi et al. [30] at the $\operatorname{UCCSD}(T)-F 12 a / c c-p V T Z-F 12 / / M 06-2 X / 6-311++G(d, p)$ level of theory using master equation analysis. The activation energies for a number of reaction classes, including $\mathrm{R}+\mathrm{O}_{2} \rightarrow$ olefin $+\mathrm{HO}_{2}, \mathrm{RO}_{2} \leftrightarrow Q O O H$, and $\mathrm{O}_{2} \mathrm{QOOH}$ decomposition, were reduced in [28] (by 1.0, 0.6 and $1.5 \mathrm{kcal} / \mathrm{mol}$, respectively) in order to improve agreement with ignition delay data in that work. Thermodynamic properties of intermediate species and products are either computationally determined or calculated using Benson's group additivity method [51] as implemented in THERM software [52]. Quantum mechanical calculations were used to calculate the thermodynamic data of all chemical species lying on the potential energy surface of $\mathrm{CPT}+\mathrm{O} 2$, such as the cyclopentyl peroxy radical (CPTO2J), the hydroperoxycyclopentylperoxy radicals (CPT1Q2J and CPT1Q3J), and the cyclic ethers (CPTYO12 and CPTYO13), while THERM was used to estimate the thermodynamic data for all other species in the CPT model.

\subsection{Methylcyclopentane Kinetic Model}

A detailed low- and high-temperature mechanism of methylcyclopentane oxidation is developed based on analogies with cyclopentane. Although pressure-dependent rate coefficients of low-temperature oxidation of CPT are available from Al Rashidi et al. [30], only the high-pressure limit rate coefficients are used by analogy for MCP since formally direct reactions are excluded from the mechanism. Cyclopentane analogies do not apply to 
the low-temperature reactions involving the methyl group of MCP. Therefore, the rate coefficients of these reactions, which include alkyl peroxy/hydroperoxy alkyl isomerization, cyclic ether formation, and QOOH dissociation to carbonyl+olefin $+\mathrm{OH}$ are assigned based on the rate rule developed by Villano and coworkers [53,54]. All $\mathrm{HO}_{2}$-elimination reactions from $\mathrm{RO}_{2}$ and $\mathrm{QOOH}$ species are assigned rate coefficients based on rate rules from [53] and [54], respectively. As for the kinetics of $\mathrm{O}_{2}$-addition to alkyl radicals, these are assigned based on rate rules from [55] for cases where analogy with CPT does not apply, namely the addition of $\mathrm{O}_{2}$ to the primary and tertiary radicals of $\mathrm{MCP}$, while the addition to secondary radicals of $\mathrm{MCP}$ is analogous to CPT. The same rate coefficients are used for the $\mathrm{O}_{2}$-addition to $\mathrm{QOOH}$ species reaction class, with pre-exponential factors that are halved, based on the findings of Goldsmith et al. [56]. For $\mathrm{O}_{2} \mathrm{QOOH}$ species, only isomerization reactions involving the migration of $\mathrm{H}$-atoms at the $\alpha$-site relative to the $\mathrm{OOH}$ moiety are considered. These reactions lead to the formation of ketohydroperoxide species and $\mathrm{OH}$ radicals, and their rate coefficients are assigned based on those of $\mathrm{RO}_{2} / \mathrm{QOOH}$ isomerization; however, to account for the weakness of $\mathrm{C}-\mathrm{H}$ bonds $\alpha$ to $\mathrm{OOH}$ groups, the activation energies of these reactions are reduced by 8.6 and $2.2 \mathrm{kcal}$ for 5 - and 6 -membered ring transitions, respectively [57]. No activation energy corrections are applied to 7-membered ring transitions [57]. Finally, the rates of $\mathrm{O}-\mathrm{O}$ scission reactions of hydroperoxide and ketohydroperoxide species are taken from the computational study of Jalan et al. [58].

The high-temperature pyrolysis and oxidation reactions of MCP that are included in the mechanism are unimolecular decomposition, $\mathrm{H}$-abstraction, $\beta$-scission and $\mathrm{H}$-migration. The rate coefficients of unimolecular decomposition of C-C in MCP are assigned based on analogies with CPT [30], except for the decomposition of (C2) C-CH3 bond for which Sarathy et al.'s [59] rate rule is used. The unimolecular decomposition reactions of C$\mathrm{H}$ bonds are written in the exothermic recombination direction and their kinetics are assigned based on the computational work of Harding et al. [60]. Sarathy et al.'s [59] rate rules are used for all $\mathrm{H}$-abstraction reactions except for $\mathrm{H}$-abstraction by $\mathrm{OH}$ from MCP whose site-specific kinetics have been studied experimentally and theoretically by Sivaramakrishnan and Michael [50]. The rate coefficients of $\mathrm{C}-\mathrm{C}$ and $\mathrm{C}-\mathrm{H} \beta$-scission reactions are assigned by analogy with CPT [10], and analogy with 2-methylhex-3-yl is used for the scission of the (C2)C-CH3 
bond. Pressure-dependence effects are included for these reactions. The only H-migration reaction of

methylcyclopentyl radicals included in the mechanism is 5-membered ring transition from a secondary site to a primary site, and rate coefficients from Tsang et al. [61] are used. Other transition state ring structures are improbable due to energy constraints.

\subsection{Results}

\subsection{Experiments}

\subsubsection{Cyclopentane}

The experiments with cyclopentane are conducted using three different dilution levels $(12 \%, 16 \%$, and $21 \% \mathrm{O}_{2}$ synthetic air composition and a constant equivalence ratio of $\phi=1$ ), two different compressed pressures ( 20 and 50 bar). For the lowest temperatures the diluent is nitrogen, while for the highest temperatures a ratio of 3:1 of argon to nitrogen is used, except for the $12 \% \mathrm{O}_{2}$ experiments where a ratio of $3: 2$ is used. The overall compressed gas temperature range covered is Tc $~ 700-980 \mathrm{~K}$. With the interest of capturing conditions most relevant to engine operation, the dilution levels are chosen to partially replicate the dilution effects of exhaust gas recirculation [62], and the impact of boosting is captured by the higher compressed pressure experiments.

The composition of each test mixture is listed in Table 1. As highlighted earlier, tests with Mixtures 1-3 utilize an intermediate, unoptimized hydraulic stop design which results in slightly faster rates of compression than later tests, with $\mathrm{t}_{\mathrm{comp}}=13.5 \mathrm{~ms}$ and $\mathrm{t}_{50}=1.25 \mathrm{~ms}$ at $\mathrm{Pc}=50$ bar.

Table 1. Summary of mixture compositions (mole fractions) used in this study.

\begin{tabular}{|c|c|c|c|c|c|c|}
\hline Mixture & CPT & MCP & ECP & $\mathbf{O}_{\mathbf{2}}$ & $\mathbf{N}_{\mathbf{2}}$ & $\mathbf{A r}$ \\
\hline 1 & 0.0275 & 0.0000 & 0.0000 & 0.2056 & 0.7661 & 0.0000 \\
\hline 2 & 0.0273 & 0.0000 & 0.0000 & 0.2054 & 0.4774 & 0.2897 \\
\hline 3 & 0.0273 & 0.0000 & 0.0000 & 0.2048 & 0.1889 & 0.5790 \\
\hline 4 & 0.0209 & 0.0000 & 0.0000 & 0.1570 & 0.8223 & 0.0000 \\
\hline 5 & 0.0208 & 0.0000 & 0.0000 & 0.1550 & 0.2057 & 0.6185 \\
\hline 6 & 0.0157 & 0.0000 & 0.0000 & 0.1174 & 0.8665 & 0.0000 \\
\hline 7 & 0.0157 & 0.0000 & 0.0000 & 0.1177 & 0.3463 & 0.5203 \\
\hline 8 & 0.0000 & 0.0132 & 0.0000 & 0.1184 & 0.8684 & 0.0000 \\
\hline 9 & 0.0000 & 0.0132 & 0.0000 & 0.1183 & 0.3471 & 0.5214 \\
\hline 10 & 0.0000 & 0.0000 & 0.0113 & 0.1179 & 0.8700 & 0.0000 \\
\hline 11 & 0.0000 & 0.0000 & 0.0113 & 0.1187 & 0.3478 & 0.5223 \\
\hline
\end{tabular}






An example of the measurements is illustrated in Fig. 4 for the Tc $=910 \mathrm{~K}$ case covering the three levels of dilution and two pressures. There are several important features evident in these pressure traces. First, data are shown for two repeated shots at the same conditions, and these generally exhibit good consistency. While small variability early in the compression process can be seen in the $\mathrm{Pc}=50$ bar traces, the end-of-compression profiles are nearly identical for each shot, with good agreement also exhibited compared to the non-reactive experiments. Second, as discussed earlier, the post-ignition "dip" observed for the tests at $21 \%$ and $16 \% \mathrm{O}_{2}$ conditions at $\mathrm{Pc}=50$ bar is due to piston rebound; it can be seen though that this occurs after most of the heat is released. Third, due to the algorithms within the DAQ card and that used to post-process these data, small disturbances are introduced into some of the signals just prior to main ignition, visible as a point-to-point oscillations. These are only significant in tests where the rates of heat release at ignition are very high (e.g., Mixes 3 and 5 at Pc $=50$ bar in Fig.4), and do not influence the determination of $t_{0}, T c$, or $\tau$, but could affect HRR calculations at these conditions. Finally, it can be seen that the reactivity of the charge increases with higher pressure, and decreases with higher dilution. These trends are consistent with known low temperature autoignition behavior $[63,64]$, which can be attributed to increased concentrations of reactants and thus overall reaction rates; $\mathrm{RO}_{2}$ chemistry enhances this at lower, e.g., NTC temperatures [64]. 
Figure 5 summarizes the measured first-stage and main ignition delay times for cyclopentane as functions of the inverse compressed temperature. Tables S1-3 are provided as Supplementary Material and list the ignition times for all of the individual tests. Representative error bars, as discussed in Section 2.2, are included at the $12 \% \mathrm{O}_{2}$ condition for reference. Note that the \pm 0.4 ms uncertainty in $\tau$ is only visible at short ignition delay times, e.g., $<5 \mathrm{~ms}$. At the highest temperatures, it is noted that the measurements for Mix 3 converge with the shock tube data of Daley et al. [21], demonstrating that there is cross-facility consistency in these datasets. Lines are provided in Fig. 5 to illustrate the model results, and these are discussed in Section 4.2.


Figure 5. Ignition delay times, (a) main at $P c=20$ bar, (b) main at $P c=50$ bar, and (c) first-stage at Pc $=50$ bar, presented as a function of inverse temperature for stoichiometric cyclopentane mixtures covering three dilution levels and two pressures. Symbols indicate experimental measurements (filled for $P c=20$ bar, open for $P c=50$ bar); lines are simulation results. Tests with MIHR are denoted by crosses where black curves are hand-drawn in (b) to identify the lower bounds of chemical ignition delay, as discussed in the text. Note that the simulations do not exhibit first-stage ignition at any condition. 
The $\mathrm{Pc}=20$ bar results in Fig. 5(a), which are generally at $\mathrm{Tc}>830 \mathrm{~K}$, indicate Arrhenius behavior across most of the measurements, while the $\mathrm{Pc}=50$ bar results shown in Fig. 5(b), which cover a wider range of temperature, exhibit clear NTC behavior. A few data points are included at $\mathrm{Pc}=20$ bar with $\mathrm{T}<830 \mathrm{~K}$, and these seem to also confirm NTC behavior at this lower pressure, but the heat release behavior for these tests indicate either mild ignition, or weak ignition suggestive of significant boundary layer growth. For these tests where $\tau>$ $300 \mathrm{~ms}$, the adiabatic core hypothesis is probably not valid.

Overall, it appears that the effect of pressure is more pronounced than the effect of dilution, where the trends observed in the dataset can be quantified via assumed power-law functionalities [65]. Both influences are most prominent in the NTC region. In many previous studies, it is likely that NTC behavior has not been observed because the temperatures were too high [20-22], and/or the pressures too low [24] for the experimental time scales. It is possible that NTC behavior of cyclopentane could become evident at highly boosted conditions utilized with advanced spark- and compression-ignited engines.

Two-stage ignition, including marked low temperature heat release, as identified in Fig. 3, is observed in some of the CPT experiments at Pc $=50$ bar. However, as can be seen in Figs. 3 and 5(c), these events occur generally very close to $\tau$, and are only detected at temperatures below that for the transition from lowtemperature to NTC conditions, e.g., $\mathrm{Tc}=755 \mathrm{~K}$ at $12 \% \mathrm{O}_{2}$. At the lowest temperatures covered in this study it is difficult to distinguish $\tau_{1}$, since the LTHR and high temperature heat release events merge, in accordance with known low temperature behavior. Within the NTC region however, there appears to be an abrupt end to observed LTHR as the temperature is increased from the transition point. Although this is somewhat challenging to confirm at the undiluted conditions, in part due to the significant shot-to-shot variation as described earlier, this feature is quite clear in the pressure records for the 16 and $12 \% \mathrm{O}_{2}$ conditions (Mixes 4 and 6 ) (as seen in Fig. 3). In these cases MIHR does not initiate until well past the time of main ignition at the transition temperature, i.e., Tc $=763$ and $755 \mathrm{~K}$, respectively. With linear, and larger cyclic alkanes on the other hand, first-stage ignition times are observed to become monotonically shorter, while main ignition times become longer (to the peak of the NTC) as the temperature increases from the NTC transition point [66]. As such, the 
current experimental observations are peculiar. Furthermore, this trend is not observed in the model results which are discussed later in Section 4.2.

Within the NTC region, most all of the cyclopentane tests exhibit mild ignition phenomena, as illustrated earlier in Fig. 3. Mild ignition has been studied extensively in shock tubes and RCMs (e.g., [67,68]), and has been observed to initiate at a single, or multiple exothermic centers. During mild ignition, the heat release process is not distributed uniformly within the reaction chamber, and deflagrative or mixed deflagrative/autoignition fronts have been detected [67]. A significant portion of the mixture, or observed as the fuel's chemical energy, can be converted by the relatively slow deflagrative processes. The case presented in Fig. 3 indicates nearly $40 \%$ of the charge reacts due to MIHR, and this requires nearly $20 \mathrm{~ms}$ to occur. The uniform, or strong ignition case by comparison, proceeds through fairly rapid LTHR ( $1.5 \mathrm{~ms}$ in duration, and $\sim 6 \%$ of the LHV) before transitioning to high temperature heat release, which requires less than $0.5 \mathrm{~ms}$ to complete. Suspended particles, contaminated surfaces and/or thermal inhomogeneities within the gas, e.g., hot spots, are suspected of causing mild ignition, however the oxidation kinetics of the fuel mixture and its associated exothermicity may also play a significant role.

Many efforts are made in the present study to eliminate possible causes of mild ignition, including the utilization of creviced pistons to suppress vortex rollup, control of the initial gas temperature uniformity, the use of an inline particle filter to eliminate possible sources of hot spots, frequent cleaning of the reaction chamber and diligent purging of the reaction chamber to eliminate inter-test contamination. However, mild ignition is still observed in nearly every single test within the NTC region for this fuel, at all dilution levels. Non-uniform ignition is not observed for any of the methylcyclopentane or ethylcyclopentane tests, as will be shown later. Furthermore, the same behavior has not been observed for any pure, blended, or full boiling-range fuel tests on this RCM prior to, or since the experiments with CPT. In the tests where mild ignition is observed, the physics inside the reaction chamber, e.g., deflagrative fronts, are no longer straightforward to model, making comparison with chemical kinetic models challenging in such cases [69], while the interpretation of experimental uncertainties [41] must be made with caution. However, some quantitative comparison is still 
possible. Since mild ignition in the absence of compositional non-uniformities and significant turbulent motion shortens overall ignition delay times [70], the experimental points that contain mild ignition in this study could be considered a floor, where homogeneous, chemically-controlled ignition delays are inferred to be longer than this. This boundary for the three dilution levels is estimated by the black, hand-drawn curves presented in Fig. $5(b)$.

While the exact cause of the consistent mild ignition behavior with CPT is not known, it is useful to hypothesize one. A combination of innate temperature inhomogeneities within the adiabatic core [71,72], e.g., due to complex gas dynamic processes that could occur during the piston seating process [73], and the propensity of CPT to form resonantly stabilized radicals such as cyclopentenyl, allyl, etc. [10,74] could create an environment in which thermal non-uniformities cannot be homogenized and thus flame kernels have sufficient time to develop and propagate before the onset of chemical ignition. Cyclopentane's unique chemistry, which may facilitate this, is discussed further in Section 4.2. It is recognized that this explanation is speculative and in need of further investigation.

\subsubsection{Substituted Cyclopentanes}

The reactivity trends of cyclopentane are next compared to the observed trends for the substituted naphthenes, methylcyclopentane and ethylcyclopentane. Experiments with MCP and ECP are conducted spanning the same temperature and pressure as with cyclopentane, but only at the highest dilution level, since ECP is much more reactive than CPT, and this is the only condition that allows direct comparison between the three fuels. The exact compositions of the test mixtures studied are presented in Table 1. Representative experimental pressure traces and derived heat release rates for MCP and ECP are compared to CPT in Fig. 6, at two different compressed conditions. No post-ignition piston movement is detected in these tests due to the lower peak pressures at ignition. The measured first-stage and main ignition times are presented in Fig. 7 as functions of inverse compressed temperature for the three naphthenes. 



Figure 6. Representative (a) pressure traces, and (b) heat release rates for non-reacting and reacting stoichiometric cyclopentane (CPT), methylcyclopentane (MCP) and ethylcyclopentane (ECP) mixtures at $12 \% \mathrm{O}_{2}$ illustrating the influence of ring substitution at a low and high temperature, and high and low pressure, respectively. For clarity, in (a) the low temperature results are vertically offset by +50 bar, while in (b) the high temperature results are vertically offset by $+0.5 \mathrm{~ms}^{-1}$.

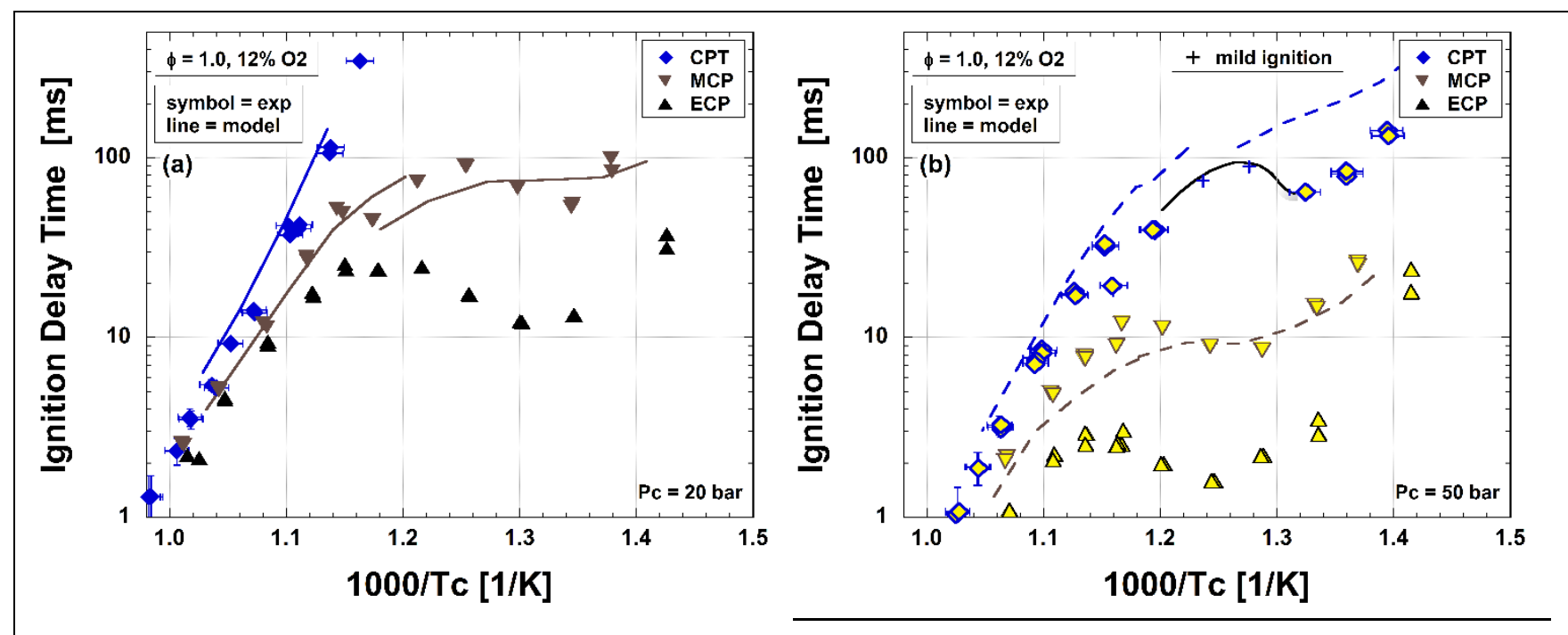






Figure 7. Ignition delay times, (a) main at $P c=20$ bar, (b) main at $P c=50$ bar, and (b) first-stage at $P c=20,50$ bar, presented as a function of inverse temperature for stoichiometric CPT, MCP and ECP mixtures at $12 \% \mathrm{O}_{2}$ and two compressed pressures. Symbols indicate experimental measurements; lines are simulation results. CPT tests with MIHR are denoted by crosses in (b) with a black curve hand-drawn to illustrate the lower bounds of chemical ignition delay, as discussed in the text.

As observed in previous works $[8,9,25,26]$ and seen in Figs. 6 and 7 , the substitution of a methyl, or an ethyl group into the ring of the naphthene significantly increases the reactivity of the molecule. The impact of side-chain substitution is most pronounced in the NTC region, with almost two orders of magnitude difference in $\tau$ between CPT and ECP, with MCP falling in between. It is interesting to note that at the highest temperatures of the experiments and $\mathrm{Pc}=20 \mathrm{bar}$, where $\tau$ for the different molecules almost collapse on top of each other. Also apparent in Fig. 7 is that in the NTC region, the temperature span for MCP and ECP occurs over a broader and slightly higher range than for CPT (e.g., $800-900 \mathrm{~K}$ versus $~ 750-815 \mathrm{~K}$, respectively), at Pc $=50$ bar. In addition, unlike what is observed in the CPT experiments, the first-stage ignition times follow more typical, linear alkane behavior, extending into the NTC region and becoming monotonically shorter than $\tau$. Furthermore, there are no instances of non-uniform ignition detected in the MCP and ECP tests.

Increased reactivity of $\mathrm{MCP}$ and $\mathrm{ECP}$, compared to $\mathrm{CPT}$, can be attributed to the increased availability of additional low-temperature $\mathrm{RO}_{2} \leftrightarrow \mathrm{QOOH}$ isomerization pathways and subsequently more low-temperature exothermicity. Experimentally observed accumulated LTHR, as defined in Section 2.2, for all three molecules is plotted in Fig. 8 as a function of inverse temperature. It should be noted that the resolution in the DAQ system only permits LTHR as low as $\sim 2 \%$ of LHV to be quantified with confidence in this work. From this presentation, it can be seen that the extent of LTHR increases with increased side chain length. While LTHR is observed for CPT 
only at a handful of conditions at $\mathrm{PC}=50$ bar, LTHR is evident over a wider temperature range for MCP and ECP, and the magnitude of this is observed to increase with pressure. These trends are consistent with known lowtemperature reactivity behavior [63].

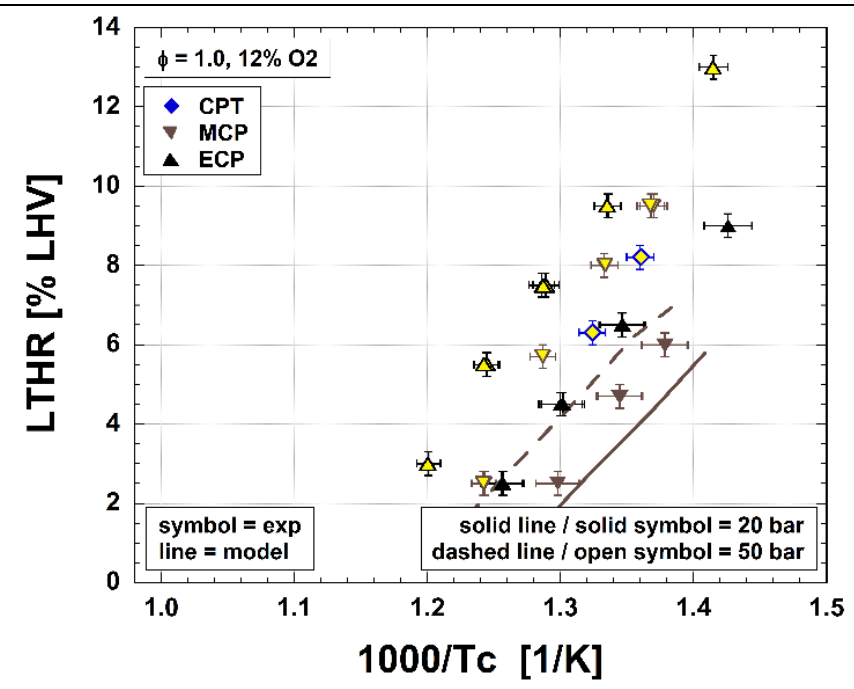

Figure 8. Observed low temperature heat release (LTHR) as a percent of the fuel's Lower Heating Value (LHV) for stoichiometric CPT, $M C P$ and ECP mixtures at $12 \% \mathrm{O}_{2}$ covering a range of temperatures and two compressed pressures. The accumulated heat release is calculated based on the procedure outlined in Section 2.2 . 


\subsection{Simulations}

\subsubsection{Cyclopentane}

The simulation results are presented above in Fig. 5 as lines covering the three dilution levels and two pressures. Representative pressure traces and calculated heat release rates are also shown in Fig. 9 where the model is compared against the experiment. In general, the overall reactivity expressed by the model compares favorably with the measurements, i.e., within a factor of 2-3 for $\tau$, and the trends with dilution and pressure are captured, but there are some noticeable discrepancies. At the lowest temperatures (Tc $=700-760 \mathrm{~K})$ the model is less reactive than the measurements. Furthermore, there is no evidence of two-stage ignition or low temperature heat release. In the NTC region $(\mathrm{Tc}=760-850 \mathrm{~K})$ the model indicates positive temperature dependence, which is unlike the experimental behavior. At higher temperatures ( $\mathrm{Tc}=850-980 \mathrm{~K})$ the reactivity is fairly consistent with the measurements.

The pressure-time and HRR histories presented in Fig. 9 are shown at the transition between lowtemperature and NTC regions. Note that the HRRs for the model are derived according to Eq. (2), but are presented offset vertically by $+0.5 \mathrm{~ms}^{-1}$ in order to visualize the differences. The results illustrate the differences in main ignition time between the experiment and model, as well as the different preliminary exothermic behavior. As discussed in Fig. 3, the reactive experiments closely follow the non-reacting traces up to the point of first-stage heat release, which occurs shortly before $\tau$. This is best seen at the $12 \% \mathrm{O}_{2}$ condition. The model, on the other hand, exhibits no first-stage heat release, but instead a period of relatively slow heat release, and fairly slow pressure rise before the main ignition. 

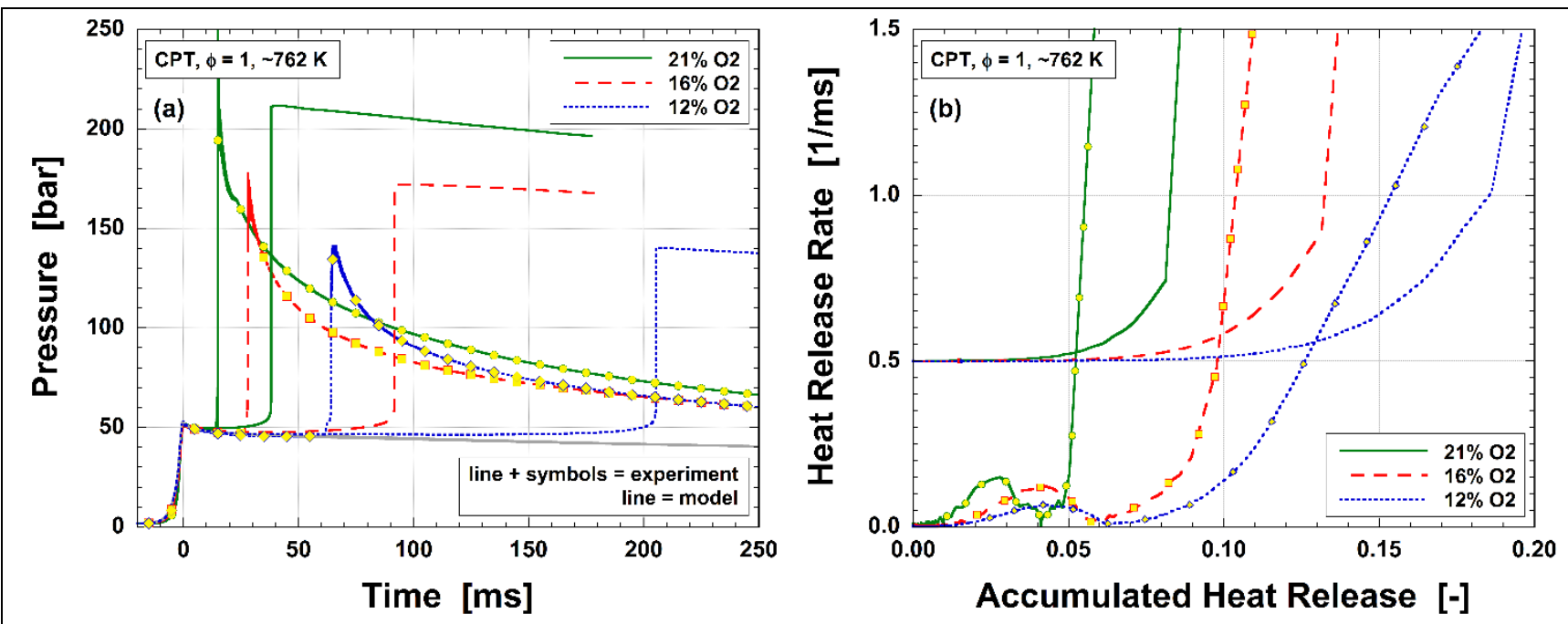

Figure 9. Experimental and modeled (a) pressure-time histories, and (b) heat release rates for non-reacting and reacting stoichiometric cyclopentane mixtures covering three dilution levels, at Tc = 762 $\mathrm{K}$ and Pc $=50$ bar. Lines plus symbols are measurements, while lines with no symbols are model results. Note that, for clarity in (b), HRRs of the model results are offset by $+0.50 \mathrm{~ms}^{-1}$.

The present results indicate that modifications are needed in the model in order to improve quantitative agreement with the RCM data, and specific examples are identified shortly. However, because the overall reactivity trends are generally captured and reasonable agreement has been seen with Jet Stirred Reactor (JSR) speciation data [10], the model is used to draw insight into the underlying chemistry of CPT autoignition and identify potential sources for the observed trends.

Sensitivity and rate of production (ROP) analyses are performed to identify important decomposition pathways predicted to control reactivity at low $(700 \mathrm{~K})$ and high $(920 \mathrm{~K})$ temperatures, for the most diluted and undiluted conditions, at $\mathrm{Pc}=50$ bar. Sensitivity analyses are conducted at times corresponding to 85\% fuel consumption, occurring just before the onset of main ignition to identify important reactions. Then, a brute force sensitivity analysis is conducted, as described below. ROP analyses are conducted at times corresponding to $20 \%$ fuel consumption. Figure 10 shows the primary degradation pathways of CPT, as determined by ROP analyses for the $12 \% \mathrm{O}_{2}$ condition. For the subsequent discussion, the reader should refer to this figure to identify the molecular structure of various species mentioned in the text. 




At both temperatures, CPT is completely converted to the cyclopentyl radical (CYC5H9) via $\mathrm{H}$ -

abstraction. The main abstracting species are $\mathrm{OH}$, followed by $\mathrm{HO}_{2}, \mathrm{H}$ and $\mathrm{O}$. At $700 \mathrm{~K}, \mathrm{CYC} 5 \mathrm{H} 9$ mainly undergoes $\mathrm{O}_{2}$-addition (94.4\%) to form the cyclopentyl peroxy radical (CPTO2J). Due to few available paths for isomerization in CPT $[6,8,9]$, almost half $(51.5 \%)$ of the $\mathrm{RO}_{2}$ radicals undergo $\mathrm{HO}_{2}$-elimination leading to cyclopentene (CYC5H8). The low-temperature chain branching pathway of CPTO2J, typically seen via isomerization to CPT1Q3J and second $\mathrm{O}_{2}$ addition accounts for $25.4 \%$ of the total CPTO2J consumption, with the 6-membered ring transition state isomerization to CPT1Q3J being the major pathway (24.5\%), as shown in Figure 10 . At $700 \mathrm{~K}$, almost all of the hydroperoxyalkylperoxy radicals produced undergo second $\mathrm{O}_{2}$-addition, and ultimately lead to ketohydroperoxides. The predominance of the pathway leading to unreactive species, cyclopentene and $\mathrm{HO}_{2}$ radicals, is the likely explanation for the low reactivity of cyclopentane observed 
experimentally here and in prior studies. In addition, these findings are consistent with the emissions data in the motored engine tests of Yang et al. $[8,9,25,26]$ where conjugate olefins were observed.

The production of $\mathrm{CYC} 5 \mathrm{H} 8$ is also important at $920 \mathrm{~K}(81.5 \%)$, and occurs mainly via addition of $\mathrm{O}_{2}$ to cyclopentyl radicals either directly (36.1\%), or indirectly, through the formation of the cyclopentyl peroxy radical (41.8\%). Interestingly, $\mathrm{C}-\mathrm{C}$ and $\mathrm{C}-\mathrm{H} \beta$-scission pathways of cyclopentyl radicals account for only $7.0 \%$ of the total consumption pathways at $920 \mathrm{~K}$. Once produced, $\mathrm{CYC5H} 8$ undergoes $\mathrm{H}$-abstraction reactions to give resonantly stabilized and secondary radicals $\mathrm{CYC} 5 \mathrm{H} 71-3$ and $\mathrm{CYC} 5 \mathrm{H} 71-4$, respectively, with a higher production rate of the former (66.3\% and $63.7 \%$ at $700 \mathrm{~K}$ and $920 \mathrm{~K}$, respectively). The $\mathrm{C}-\mathrm{C} \beta$-scission of $\mathrm{CYC} 5 \mathrm{H} 71-3$, dominant at high temperatures (63.8\%), leads to resonantly stabilized and non-reactive radicals $\mathrm{C}^{*} \mathrm{CC} * \mathrm{CCJ}$ and $\mathrm{C}^{*} \mathrm{CCJC} \mathrm{C}^{*} \mathrm{O}$. Meanwhile, at low temperatures, the dominant reaction pathway of $\mathrm{CYC} 5 \mathrm{H} 71-3$ is the chain branching $\mathrm{HO}_{2-}$ addition to form $\mathrm{OH}$ radicals and the corresponding alkoxy radicals (56.1\%).

A competing path for $\mathrm{CYCC} 5 \mathrm{H} 9$ consumption is $\mathrm{C}-\mathrm{C}$ scission to produce $\mathrm{C} 5 \mathrm{H} 91-5$ non-cyclic radicals, and this becomes more important at higher temperatures (10.0\% to $22.3 \%$ increase). This species is particularly interesting because it is responsible for generating high concentrations of allyl radicals (C3H5-A) (93\% and $97.7 \%$ at $700 \mathrm{~K}$ and $920 \mathrm{~K}$, respectively). These radicals can recombine to form 1,5-hexadiene, or scavenge other radicals. Allyl radicals are incredibly stable and can persist in the reacting mixture until relatively high temperatures are reached [75]. In the present system, they primarily recombine into 1,5-hexadiene, which is a chain terminating step, or they react with $\mathrm{HO}_{2}$ radicals in a chain branching manner to produce $\mathrm{OH}$ and alkoxy radicals. In the previous work of Al Rashidi et al. [10], the competition between these two reaction pathways led to unique "NTC-like" behavior of cyclopetane in a jet-stirred reactor at relatively high temperatures. The reactivity of cyclopentane was suppressed in the JSR at fuel rich conditions and intermediate temperatures (900$1100 \mathrm{~K})$, as evidenced by decreased consumption of the fuel. Allyl radicals can form more directly from the ring opening of cylcopentane [74], though this is likely to only be an important pathway at high temperatures.

The propensity of cyclopentane to form cyclopentenyl and other resonantly stabilized radicals may contribute to the tendency for non-uniform ignition to occur in the NTC region of the present experiments. 
Acting as radical scavengers, these species could help suppress preliminary heat release in the reacting mixture, where, as seen in Figs. 5 and 8, LTHR is only observed at temperatures below the transition to NTC conditions. It has been previously demonstrated experimentally by Desgroux et al. [72] and computationally by Luong et al. [76], that preliminary exothermicity, e.g., LTHR, can have a temperature leveling effect at RCM conditions. As such, innate thermal inhomogeneities within the reaction chamber [71,72], which are not homogenized due to suppressed preliminary heat release of CPT, could create post-compression conditions where flame kernel formation is facilitated and thereby consumes a significant fraction of the reacting mixture. It has been documented that fuels without LTHR, including hydrogen [77], syngas [78], ethanol [79], and toluene [80] are susceptible to mild ignition in other devices. Further investigation of CPT autoignition in the NTC region is needed to better understand the behavior observed in the present dataset, and confirm this hypothesis.

The influence of individual reactions on the predicted autoignition behavior of CPT is assessed via sensitivity analyses where these are discussed next. Brute force sensitivity analyses are performed to account for the nonlinear response of the model [81,82], where this is not captured by local temperature sensitivity analyses. To facilitate this, temperature sensitivities are first determined to identify the most important reactions in the mechanism based on their $|d| \mathrm{n} T / d k_{i} \mid$ sensitivity coefficients. Brute force sensitivity coefficients $(\sigma)$ are then calculated according to the following equation:

$$
\sigma_{i}=\frac{\log \left(\frac{\tau_{i}^{+}}{\tau_{i}^{-}}\right)}{\log \left(\frac{2.0}{0.5}\right)}
$$

where $\tau_{i}^{+}$and $\tau_{i}^{-}$represent ignition delay times calculated with the rates of reaction, " $i$ " multiplied by factors of 2.0 and 0.5 , respectively [83]. Positive sensitivity coefficients signify an increase in $\tau$, i.e. a decrease in reactivity, with increasing reaction rate, and vice versa.

Figure 11 depicts reactions with the highest positive or negative sensitivity coefficients at the investigated conditions. As is readily observed here the same reactions are important for the most diluted and undiluted mixtures (12 and $21 \% \mathrm{O}_{2}$, respectively) with only minor differences in the magnitudes of the sensitivity coefficients. This is consistent with Fig. 5 wherein it is shown that the effect of dilution on cyclopentane 
reactivity is small both at low and high temperatures, such as $700 \mathrm{~K}$ and $920 \mathrm{~K}$. Although the $\mathrm{RO}_{2} \leftrightarrow \mathrm{QOOH}$ isomerization reaction (CPTO2J $\leftrightarrow$ CPT1Q3J) is not the dominant reaction pathway of CPTO2J species at $700 \mathrm{~K}$

(Fig. 10), it is the most reactivity-promoting reaction. As discussed earlier, this is the rate controlling reaction for the primary low-temperature chain branching pathway and the associated preliminary heat release. Small changes to its rate constant significantly alter the predictions of $\tau$. Subsequent reactions in this pathway, covering the formation of ketohydroperoxide $(\mathrm{CPTQ} 3 \mathrm{QJ} \rightarrow \mathrm{CPT} 1 * \mathrm{O} 3 \mathrm{Q}+\mathrm{OH})$ and its decomposition $(\mathrm{CPT} 1 * \mathrm{O} 3 \mathrm{Q} \rightarrow$ $\mathrm{C} 2 \mathrm{H} 4+\mathrm{CO}+\mathrm{CH} 2 \mathrm{CHO}+\mathrm{OH})$, are also clearly important at low temperatures.

Concerted elimination of $\mathrm{HO}_{2}$ from cyclopentyl peroxy radical (CPTO2 $\rightarrow \mathrm{CYC} 5 \mathrm{H} 8+\mathrm{HO} 2$ ) is the most important chain termination reaction, as indicated by the large positive sensitivity coefficient in Fig. 11. Formation of cyclopentene $(\mathrm{CYC} 5 \mathrm{H} 8)$ is the dominant reaction pathway at both low and high temperatures, as indicated in Fig. 10. To improve the accuracy of chemical kinetic predictions of CPT reactivity, further study is suggested on the chemical kinetics of cyclopentene at engine relevant conditions, but this is beyond the scope of the present study. Other important reactivity controlling reactions at $700 \mathrm{~K}$ include $\mathrm{H}$-abstraction reactions from $\mathrm{CPT}$ by $\mathrm{OH}$ and $\mathrm{HO}_{2}$ radicals that promote reactivity, and the reactivity-suppressing reaction of $\mathrm{HCO}+\mathrm{O} 2 \leftrightarrow \mathrm{CO}+\mathrm{HO} 2$. The formally direct pathway of $\mathrm{CYC} 5 \mathrm{H} 9+\mathrm{O} 2 \leftrightarrow \mathrm{CYC} 5 \mathrm{H} 8+\mathrm{HO} 2$ suppresses reactivity at $700 \mathrm{~K}$ and $920 \mathrm{~K}$ for the stoichiometric, $21 \%$ and $12 \% \mathrm{O}_{2}$ mixtures.

At high temperatures $(920 \mathrm{~K})$, cyclopentane reactivity is most sensitive to the reactivity-promoting reactions of $\mathrm{H}$-abstraction by $\mathrm{HO}_{2}$ from $\mathrm{CPT}$ and $\mathrm{H}_{2} \mathrm{O}_{2}$ decomposition to two $\mathrm{OH}$ radicals, and the reactivitysuppressing reactions of concerted $\mathrm{HO}_{2}$-elimination from CPTO2J and recombination of $\mathrm{HO}_{2}$ radicals. It should be noted that the contribution of $\mathrm{HO}_{2}$ radicals to the total $\mathrm{H}$-abstraction rate from CPT is less than $20 \%$. However, $\mathrm{H}$-abstraction by $\mathrm{HO}_{2}$ leads to $\mathrm{H}_{2} \mathrm{O}_{2}$ which affects the rate of the high sensitivity chain branching $\mathrm{H} 2 \mathrm{O} 2(+\mathrm{M}) \leftrightarrow \mathrm{OH}+\mathrm{OH}(+\mathrm{M})$ reaction. 


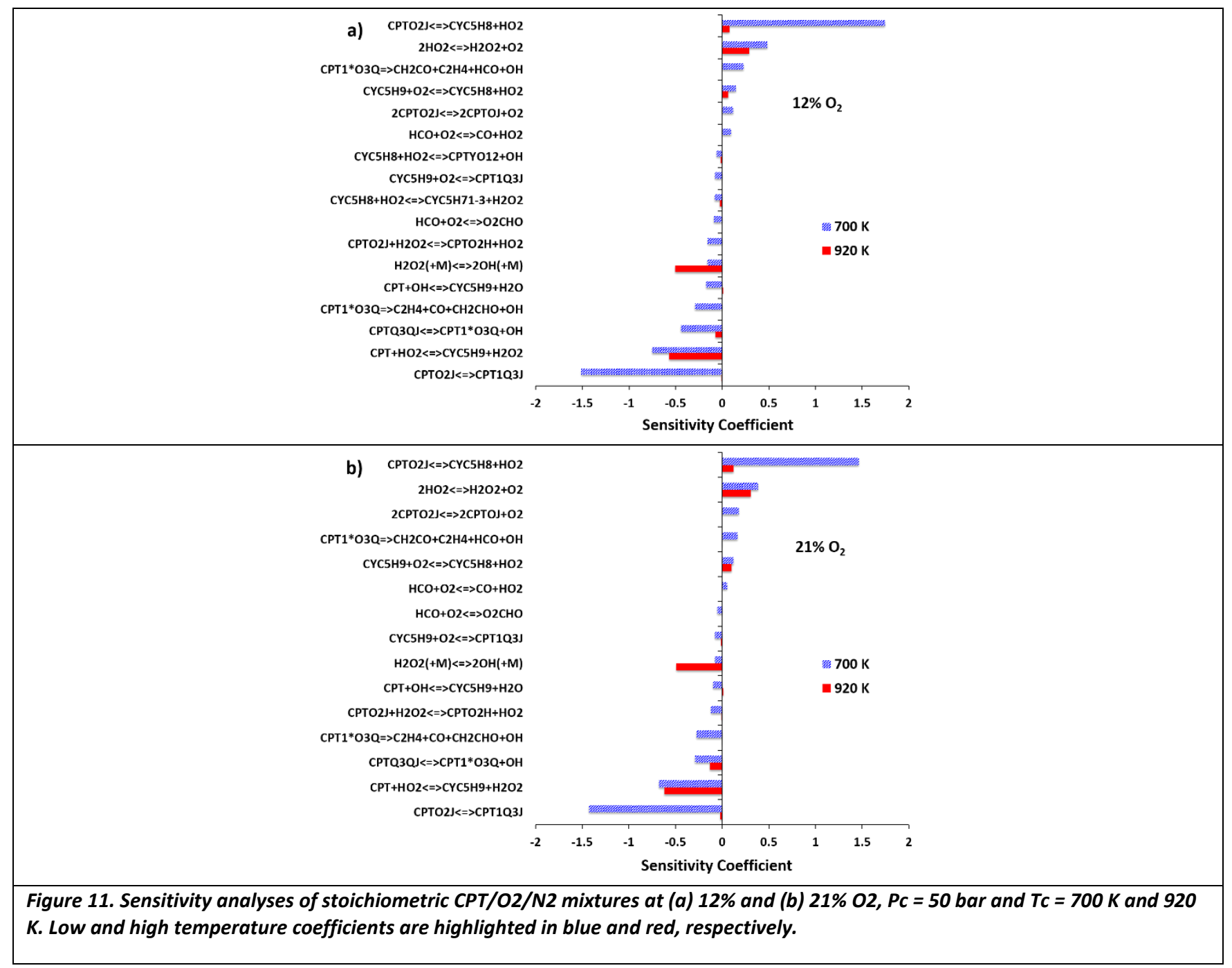

\subsubsection{Methylcyclopentane}

The overall predicted ignition delays are shown as lines in Fig. 7 at the two pressure conditions, while

Fig. 12 presents simulated pressure and heat release profiles compared to experimental measurements.

Compared to CPT, the MCP simulations better capture the reactivity trends for methylcyclopentane. At low and intermediate temperatures, the reactivity is fairly well predicted, while the model indicates an overall flatter NTC region than is seen experimentally. Furthermore, as can be seen in Figs. 8 and 12, while the overall ignition delay is correctly predicted for some points, preliminary heat-release behavior does not match experimental observations. First-stage ignition times are generally earlier in the MCP model, and the peak HRRs are much lower than the experimental measurements. The integrated LTHR is lower than the measurements at both pressure conditions. 


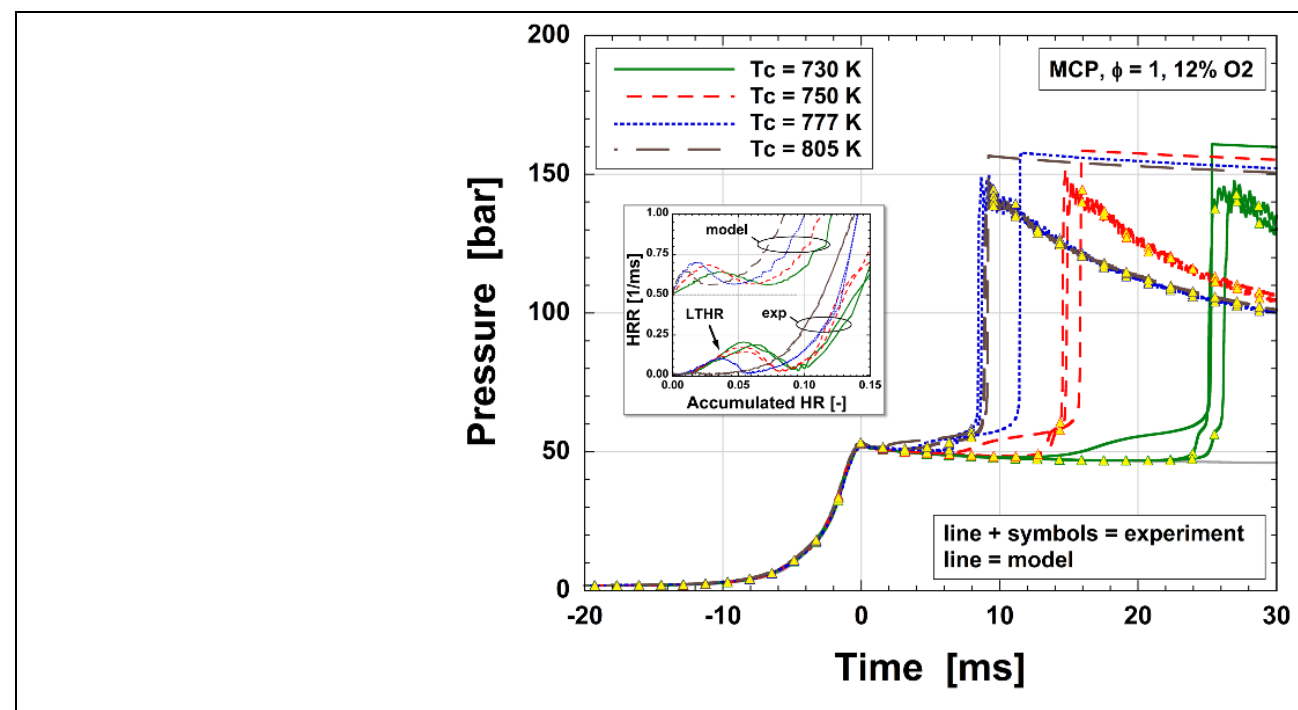

Figure 12. Example experimental and simulated pressure-time histories and heat release rates for stoichiometric MCP mixtures. For clarity, the model HRR is multiplied by a factor of 10 and offset by $+0.50 \mathrm{~ms}^{-1}$ in the inset.

As discussed in Section 3.2, only the high-pressure limit rate constants are utilized for low-temperature oxidation reactions of MCP. Considering the importance of molecular structure, pressure-dependence, and that of formally direct reactions, as seen in the case of CPT [24], more accurate, pressure-dependent kinetics for MCP oxidation are needed. However, the present model is able to elucidate some important kinetics behind the increased reactivity of $\mathrm{MCP}$, while necessary improvements are left for future work. Rate of production analysis is performed for $\mathrm{MCP}$ ignition at $12 \% \mathrm{O}_{2}$ and $\mathrm{Pc}=50 \mathrm{bar}$, and two compressed temperatures, $700 \mathrm{~K}$ and $900 \mathrm{~K}$. The sensitivity analysis is conducted at times corresponding to $~ 85 \%$ fuel consumption, just before the onset of main ignition, while ROP analysis is conducted at $\sim 20 \%$ fuel consumption. Figure 13 depicts the major degradation pathways for MCP and the important subsequent reactions. For the following discussion, the reader should refer to Fig. 13 for the molecular structure of various species named. 


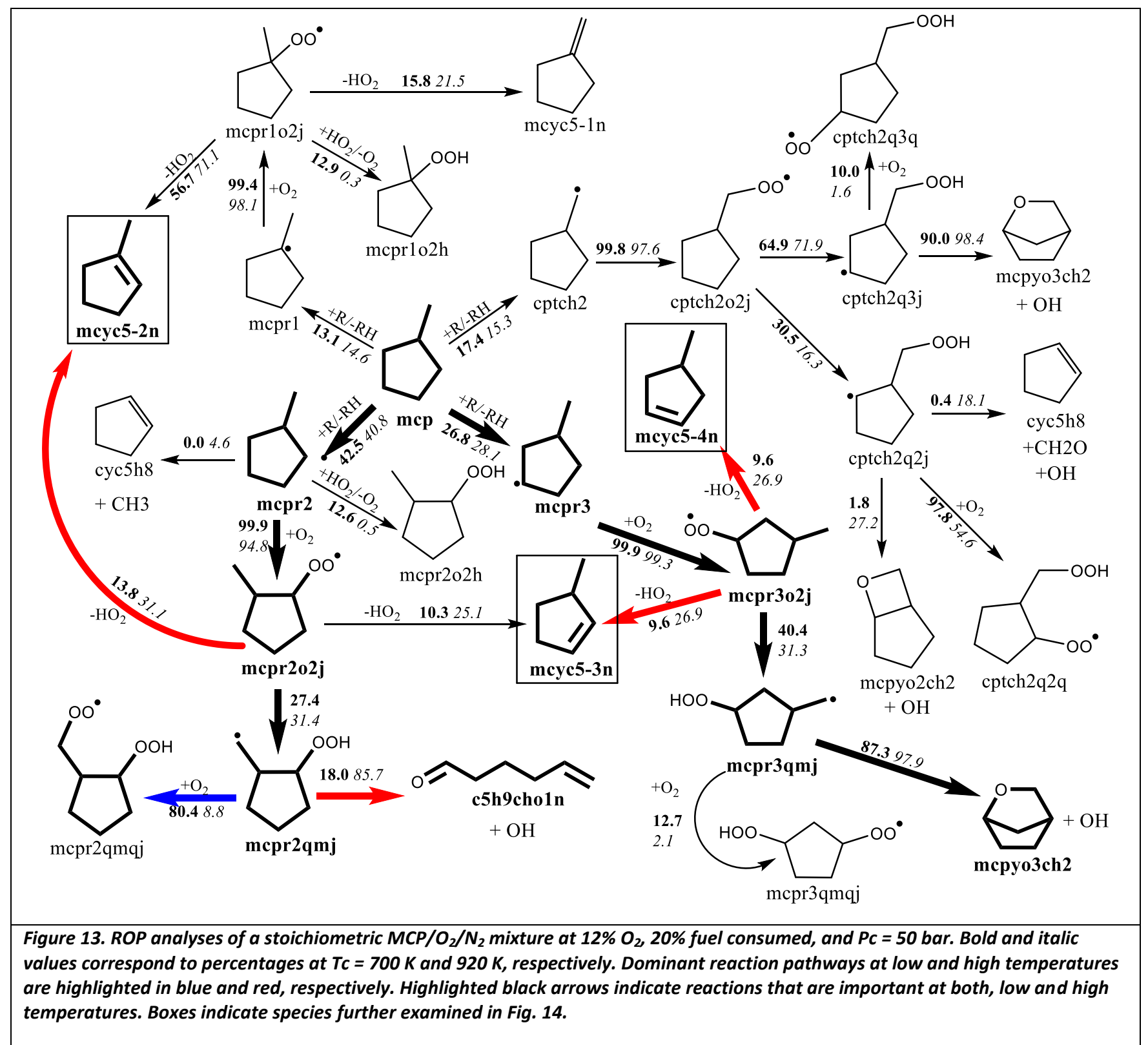

The decomposition of MCP mainly produces secondary radicals MCPR2 and MCPR3 (68 - 69\% of total consumption) at both, $700 \mathrm{~K}$ and $920 \mathrm{~K}$. Similar to $\mathrm{CPT}, \mathrm{OH}$ is the primary abstractor in these reactions. The primary and tertiary radicals, CPTCH2 and MCPR1 in Fig. 13, are consistently produced at approximately 13-18\%, regardless of temperature. At both temperatures, the dominant path of consumption (94.8-99.9\%) for all these alkyl radicals is $\mathrm{O}_{2}$ addition. For the resultant $\mathrm{RO}_{2}$ radicals, MCPR2O2J, MCPR3O2J, and CPTCH2O2J, isomerization to $\mathrm{QOOH}$ constitutes a significant portion of their consumption ( 30\%, 35\%, and 92\% respectively), opening chain propagating and branching pathways. For the $\mathrm{RO}_{2}$ radical resulting from $\mathrm{O}_{2}$ addition to the tertiary site (MCPR1, MCPR1O2J), the dominant consumption pathway is $\mathrm{HO}_{2}$ elimination, a reaction that 
tends to suppress overall reactivity. Surprisingly, the degradation pathways important at low temperatures are also important at high temperatures, with small differences in relative rates of production. The dominant reactions generally belong to the low-temperature chemistry regime (ex. $\mathrm{O}_{2}$-addition and $\mathrm{RO}_{2} \leftrightarrow \mathrm{QOOH}$ isomerization), showing that transition to the high-temperature chemistry regime occurs at temperatures higher than $920 \mathrm{~K}$.

As anticipated, this ROP analysis reveals that the substitution of a saturated side-chain into cyclopentane increases reactivity of the molecule through the availability of multiple low-temperature isomerization pathways for the $\mathrm{RO}_{2}$ radicals with the most important pathways involving the transfer of an $\mathrm{H}$ atom from the methyl group. The dominance of low-temperature chain branching pathways in MCP at $700 \mathrm{~K}$ explains the increased LTHR observed experimentally for MCP compared to CPT, with associated shorter ignition delay times. Figure 13 also reveals that, at high temperatures, the formation of cyclic olefins through $\mathrm{HO}_{2}$ elimination is another important pathway for MCP. As seen with CPT, these species can form resonantly stabilized radicals that can suppress reactivity. These results are again consistent with the experimental observations of Yang et al. $[8,9,25,26]$. 


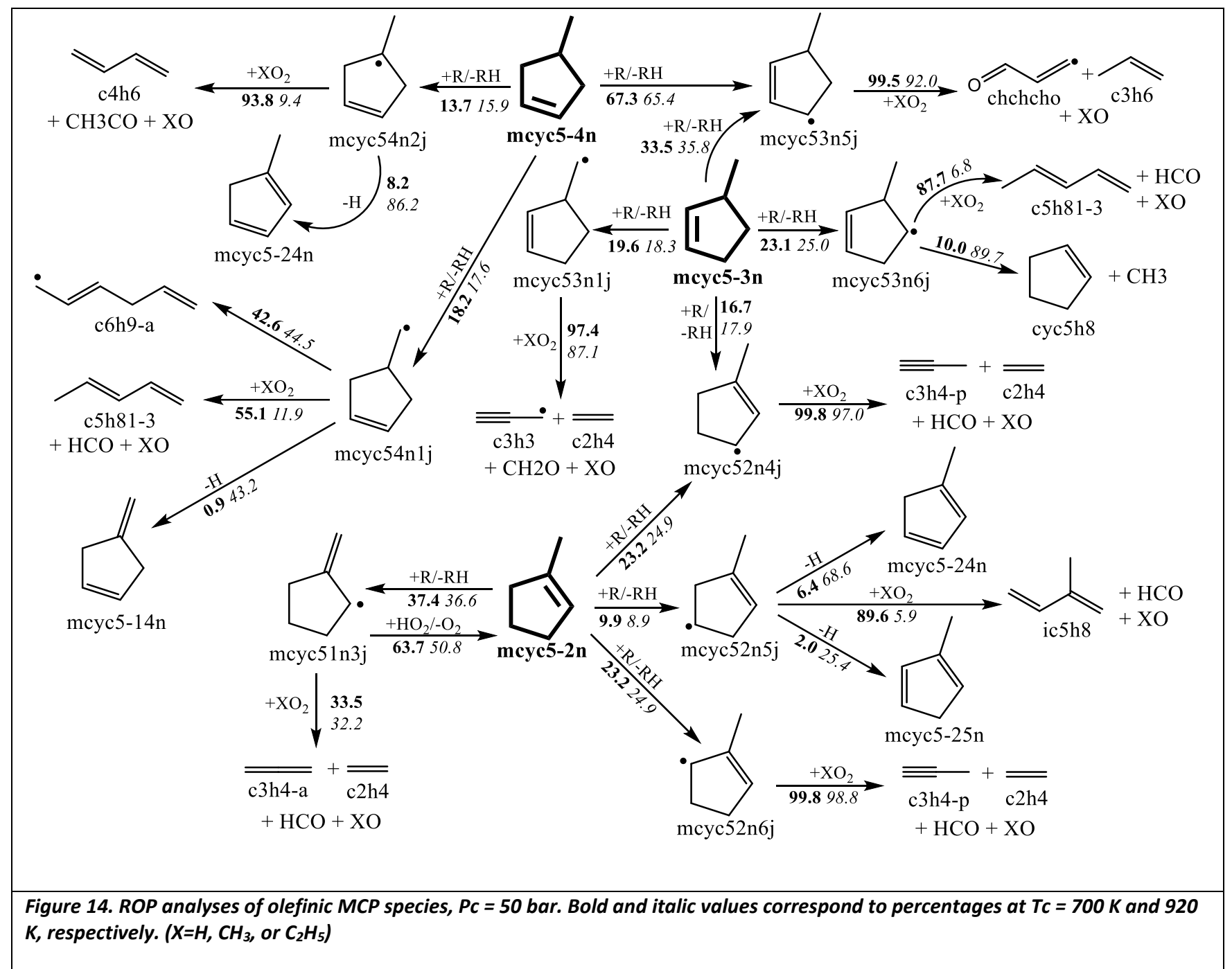

The ROP analysis performed for MCP is extended to examine the dominant decomposition pathways for the three major cyclic olefins indicated to form from MCP, including MCYC5-2N, $-3 N$, and $-4 N$, as identified by the boxes in Fig. 13. The results for these ROP analyses are presented in Fig. 14. The main degradation pathways for these cyclic olefins are via $\mathrm{H}$-abstraction (>95\%). At either temperature, the predominantly produced radicals are resonantly stabilized. Once formed, these radicals are mainly consumed by $\beta$-scission yielding polyunsaturated species, with this process more important at high temperatures, or by reaction with $\mathrm{HO}_{2}$ radicals to produce diolefins, carbonyls, and $\mathrm{OH}$ radicals.

Brute force sensitivity analyses are conducted at the same conditions as ROP analyses for CPT discussed previously, with results presented in Fig. 15. Abstraction reactions leading to primary and secondary radicals (MCPR2, MCPR3 and CPTCH2) are indicated to promote reactivity. However, the $\mathrm{H}$-abstraction reactions leading to the tertiary radical MCPR1 reduce reactivity, due to its preferred chain terminating pathways, as shown in Fig. 
13. $\mathrm{HO}_{2}$-elimination reactions suppress reactivity and are therefore shown to have positive sensitivity coefficients in Fig. 15. $\mathrm{H}_{2} \mathrm{O}_{2}$ branching to two $\mathrm{OH}$ radical, and $\mathrm{HO}_{2}$ recombination to $\mathrm{H}_{2} \mathrm{O}_{2}$ and $\mathrm{O}_{2}$ are the reactions with the lowest and highest sensitivity coefficients, indicating that these reactions are the most effective in promoting and inhibiting reactivity, respectively. Isomerization of MCPR2O2J and MCPR3O2J, decomposition of $\mathrm{MCP} 2 * \mathrm{OMQ}$ and $\mathrm{O}_{2}$-addition to $\mathrm{CPTCH} 2 \mathrm{Q} 2 \mathrm{~J}$ and $\mathrm{MCPR} 2 \mathrm{QMJ}$ are all reactivity promoting reactions, with appreciable sensitivity coefficients, particularly at $700 \mathrm{~K}$. The most important feature evident in Fig. 15 is the increased importance of multiple pathways controlling the reactivity of MCP at low temperatures.

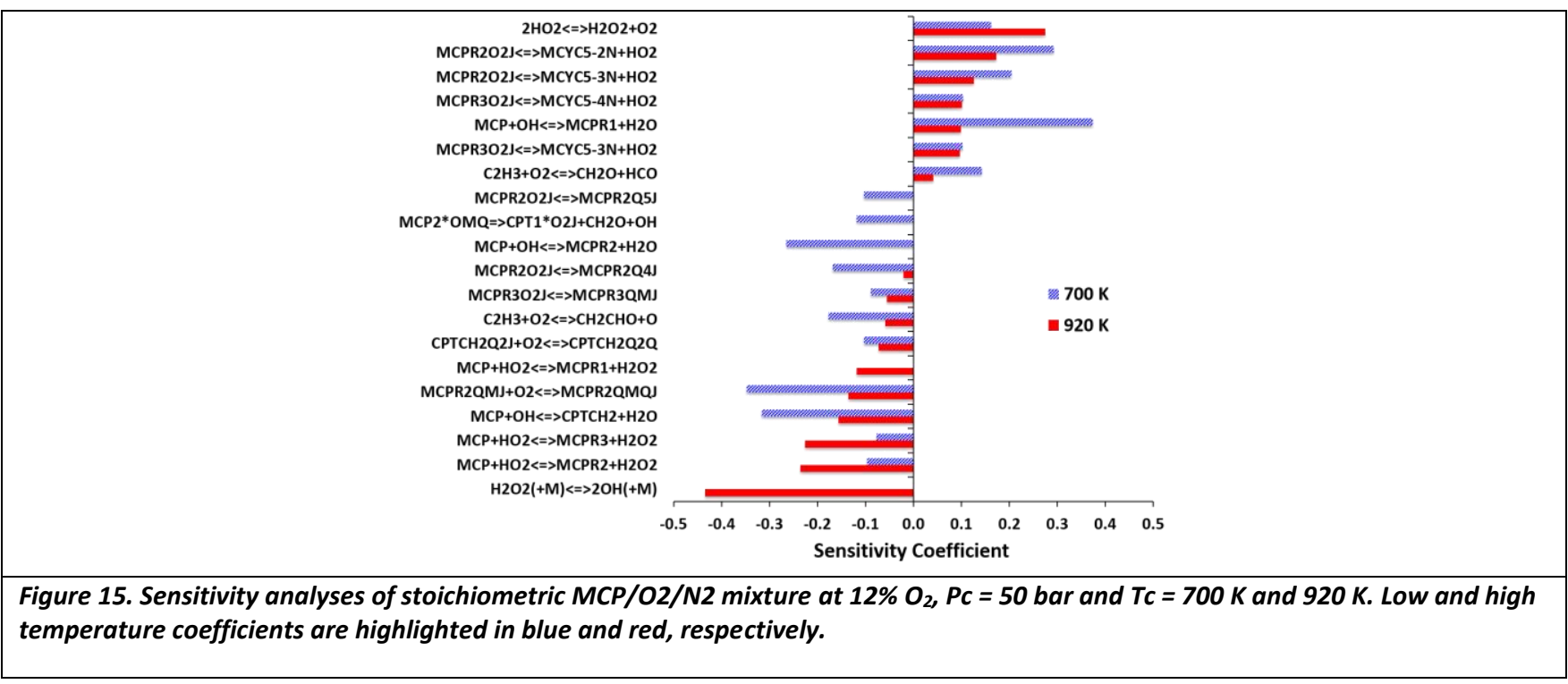

\subsection{Summary}

Experiments are conducted to explore and quantify the low temperature autoignition behavior of three 5-membered ring naphthenes, including cyclopentane, and two of its substituted analogues, methylcyclopentane and ethylcyclopentane. A rapid compression machine is used to acquire ignition delay time and preliminary heat release data over a range of engine-relevant conditions, including Tc $=700-980 \mathrm{~K}, \mathrm{P}=20$ and 50 bar, and dilution levels $\left(12 \%, 16 \%\right.$, and $21 \% \mathrm{O}_{2}$ synthetic air composition and a constant equivalence ratio of $\phi=1$ ). A recent detailed kinetic model for CPT is utilized and extended for MCP in order to interpret the reactivity trends of the three naphthenes. 
The measurements reveal that the influence of pressure and dilution, as well as ring substitution, are much more prominent at low-temperature and NTC conditions, while at intermediate temperatures the effects are muted. Furthermore, the first-stage heat release characteristics of CPT seem to be quite different than linear alkanes, as well as the substituted naphthenes. There is no evidence of typical preliminary exothermicity or LTHR for CPT in the NTC region, and this is thought to inhibit the temperature leveling of innate thermal inhomogeneities that may exist within the reaction chamber, thereby facilitating the formation/growth of flame kernels which lead to mild ignition pheneomena.

Simulations performed using the chemical kinetic model indicate that, in general, the reactivity trends are captured, and quantitative agreement with ignition delay times is in the order of a factor of 2-3.

Discrepancies exist, particularly at the lowest temperature conditions with less prominent NTC behavior demonstrated. Furthermore, there is no predicted LTHR for CPT and this does not replicate the behavior observed in the experiments, indicating that additional improvements are needed in the model. The simulations reveal the lack of important chain branching reactions for CPT at low temperatures due to the hindered isomerization process of $\mathrm{RO}_{2} \leftrightarrow \mathrm{QOOH}$, while this channel is more prominent in the substituted MCP which allows isomerizations with the methyl group. Additionally, the predicted production of cyclic olefins corroborates similar experimental observations in motored engine experiments with substituted naphthenes.

\subsection{Acknowledgements}

The submitted manuscript has been created in part by UChicago Argonne, LLC, Operator of Argonne National Laboratory (“Argonne”). Argonne, a U.S. Department of Energy Office of Science laboratory, is operated under Contract No. DE-AC02-06CH11357. The U.S. Government retains for itself, and others acting on its behalf, a paid-up nonexclusive, irrevocable worldwide license in said article to reproduce, prepare derivative works, distribute copies to the public, and perform publicly and display publicly, by or on behalf of the Government. The Department of Energy will provide public access to these results of federally sponsored research in accordance with the DOE Public Access Plan. http://energy.gov/downloads/doe-public-access-plan. This work is 
performed under the auspices of the Office of Energy Efficiency and Renewable Energy, Office of Vehicle Technology, U.S. Department of Energy, under contract number DE-AC02-06CH11357.

KAUST CCRC is grateful to Saudi Aramco for sponsoring this research under the FUELCOM program, and the Office of Sponsored Research (OSR) at KAUST under Award No. OSR-2016-CRG5-3022. The work at LLNL is supported by the U.S. Department of Energy, Vehicle Technologies Office (program managers Gurpreet Singh and Leo Breton) and performed under the auspices of the U.S. Department of Energy by Lawrence Livermore National Laboratory under Contract DE-AC52-07NA27344. The authors acknowledge the assistance of Jeffrey Santner and Toby Rockstroh for their efforts to maintain and operate ANL's tpRCM, Robert Tranter at ANL for helpful discussions, and Dr. Samah Mohamed and Mr. Tony Bissoonauth (KAUST) for help with the kinetic modeling.

\subsection{Appendix}

The chemically-derived heat release rate for the RCM experiments can be estimated based on application of the first law of thermodynamics to the gas in the reaction chamber, as described in [39] and [38] for internal combustion engine analyses. This is expressed as,

$$
H R R=\frac{\gamma}{\gamma-1} P \frac{d V}{d t}+\frac{1}{\gamma-1} V \frac{d P}{d t}-\frac{P V}{(\gamma-1)^{2}} \frac{d \gamma}{d t}+\frac{d Q_{w}}{d t}+\frac{\gamma}{\gamma-1} P V \frac{1}{N} \frac{d N_{c r v}}{d t}
$$

where $d Q_{w} / d t$ is the rate of heat loss to the walls and $d N_{c r v} / d t$ is the gas flow from the reaction chamber to the crevice. For the RCM tests, as described in $[36,84]$, heat loss and crevice flow can be approximated via experimental measurements using non-reactive mixtures, where in such cases the left-hand side of Eq. (A1) is identically zero,

$$
\left[\frac{d Q_{w}}{d t}+\frac{\gamma}{\gamma-1} P V \frac{1}{N} \frac{d N_{c r v}}{d t}\right]=-\left[\frac{\gamma}{\gamma-1} P \frac{d V}{d t}+\frac{1}{\gamma-1} V \frac{d P}{d t}-\frac{P V}{(\gamma-1)^{2}} \frac{d \gamma}{d t}\right]_{n}
$$

While this approach is not rigorously correct as the exothermicity can induce greater wall losses and additional flow to the crevice [84], this formulation provides a reasonable means to characterize and analyze the exothermic behavior. Substituting Eq. (A2) into Eq. (A1) yields, 


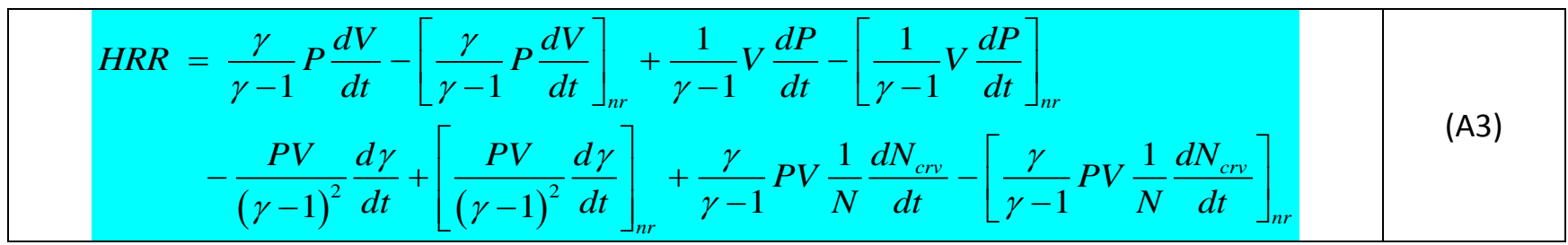

Under the constraints that the piston compression trajectory is similar between the reactive and non-reactive

tests, and the gas properties can be approximated as an average of the reactive and non-reactive mixtures Eq.

(A3) reduces to the form shown in Eq. (2). During the calculation of HRR, the composition of the reacting

mixture is varied (from reactants to products, proportional to the extent of heat release, as a fraction of LHV) to

reasonably account for changes in heat capacity, and thus $\gamma$.

\subsection{References}

[1] Alleman TL, McCormick RL, Yanowitz J. Properties of Ethanol Fuel Blends Made with Natural Gasoline. Energy \& Fuels 2015;29:5095-102. doi:10.1021/acs.energyfuels.5b00818.

[2] Mzinyati AB. Fuel-Blending Stocks from the Hydrotreatment of a Distillate Formed by Direct Coal Liquefaction. Energy \& Fuels 2007;21:2751-62. doi:10.1021/ef060622r.

[3] Christensen ED, Chupka GM, Luecke J, Smurthwaite T, Alleman TL, lisa K, et al. Analysis of Oxygenated Compounds in Hydrotreated Biomass Fast Pyrolysis Oil Distillate Fractions. Energy \& Fuels 2011;25:5462-71. doi:10.1021/ef201357h.

[4] Graça I, Lopes JM, Cerqueira HS, Ribeiro MF. Bio-oils Upgrading for Second Generation Biofuels. Ind Eng Chem Res 2013;52:275-87. doi:10.1021/ie301714x.

[5] Eaton SJ, Beis SH, Karunarathne SA, Pendse HP, Wheeler MC. Hydroprocessing of Biorenewable Thermal Deoxygenation Oils. Energy \& Fuels 2015;29:3224-32. doi:10.1021/acs.energyfuels.5b00396.

[6] Battin-Leclerc F. Detailed chemical kinetic models for the low-temperature combustion of hydrocarbons with application to gasoline and diesel fuel surrogates. Prog Energy Combust Sci 2008;34:440-98. doi:DOI 10.1016/j.pecs.2007.10.002.

[7] McEnally CS, Pfefferle LD. Experimental study of fuel decomposition and hydrocarbon growth processes for cyclohexane and related compounds in nonpremixed flames. Combust Flame 2004;136:155-67. doi:10.1016/j.combustflame.2003.09.012.

[8] Yang Y, Boehman AL, Simmie JM. Uniqueness in the low temperature oxidation of cycloalkanes. Combust Flame 2010;157:2357-68. doi:10.1016/j.combustflame.2010.06.005.

[9] Yang Y, Boehman AL, Simmie JM. Effects of molecular structure on oxidation reactivity of cyclic hydrocarbons: Experimental observations and conformational analysis. Combust Flame 2010;157:2369-79. doi:10.1016/j.combustflame.2010.04.015.

[10] Al Rashidi MJ, Thion S, Togbé C, Dayma G, Mehl M, Dagaut P, et al. Elucidating reactivity regimes in cyclopentane oxidation: Jet stirred reactor experiments, computational chemistry, and kinetic modeling. Proc Combust Inst 2017;36:469-77. doi:10.1016/j.proci.2016.05.036.

[11] Sarathy SM, Kukkadapu G, Mehl M, Javed T, Ahmed A, Naser N, et al. Compositional effects on the ignition of FACE gasolines. Combust Flame 2016;169:171-93. doi:10.1016/j.combustflame.2016.04.010.

[12] Battin-Leclerc F. Detailed chemical kinetic models for the low-temperature combustion of hydrocarbons with application to gasoline and diesel fuel surrogates. Prog Energy Combust Sci 2008;34:440-98. doi:10.1016/j.pecs.2007.10.002.

[13] Vranckx S, Lee C, Chakravarty HK, Fernandes RX. A rapid compression machine study of the low temperature combustion of cyclohexane at elevated pressures. Proc Combust Inst 2013;34:377-84. doi:10.1016/j.proci.2012.06.071.

[14] Zhang K, Banyon C, Togbé C, Dagaut P, Bugler J, Curran HJ. An experimental and kinetic modeling study of $\mathrm{n}$-hexane oxidation. Combust Flame 2015;162:4194-207. doi:10.1016/j.combustflame.2015.08.001.

[15] Knocking Characteristics of Pure Hydrocarbons. 100 Barr Harbor Drive, PO Box C700, West Conshohocken, PA 
19428-2959: ASTM International; 1958. doi:10.1520/STP225-EB.

[16] Tian Z, Zhang Y, Yang F, Huang Z. Comparative Study on Autoignition Characteristics of Methylcyclohexane and Cyclohexane. Energy \& Fuels 2015;29:2685-95. doi:10.1021/ef502714r.

[17] Tian Z, Zhang Y, Yang F, Pan L, Jiang X, Huang Z. Comparative Study of Experimental and Modeling Autoignition of Cyclohexane, Ethylcyclohexane, and n -Propylcyclohexane. Energy \& Fuels 2014;28:7159-67. doi:10.1021/ef501389f.

[18] Weber BW, Pitz WJ, Mehl M, Silke EJ, Davis AC, Sung C-J. Experiments and modeling of the autoignition of methylcyclohexane at high pressure. Combust Flame 2014;161:1972-83. doi:10.1016/j.combustflame.2014.01.018.

[19] Crochet $M$, Minetti R, Ribaucour M, Vanhove $G$. A detailed experimental study of $n$-propylcyclohexane autoignition in lean conditions. Combust Flame 2010;157:2078-85. doi:10.1016/j.combustflame.2010.04.012.

[20] Sirjean B, Buda F, Hakka H, Glaude PA, Fournet R, Warth V, et al. The autoignition of cyclopentane and cyclohexane in a shock tube. Proc Combust Inst 2007;31:277-84. doi:10.1016/j.proci.2006.07.247.

[21] Daley SM, Berkowitz AM, Oehlschlaeger MA. A shock tube study of cyclopentane and cyclohexane ignition at elevated pressures. Int J Chem Kinet 2008;40:624-34. doi:10.1002/kin.20353.

[22] Tian Z, Tang C, Zhang Y, Zhang J, Huang Z. Shock Tube and Kinetic Modeling Study of Cyclopentane and Methylcyclopentane. Energy \& Fuels 2015;29:428-41. doi:10.1021/ef502552e.

[23] Wang H, Dames E, Sirjean B, Sheen DA, Tangko R, Violi A, et al. JetSurF version 2.0, available at <http://melchior.usc.edu/JetSurF/JetSurF2.0> 2010. http://melchior.usc.edu/JetSurF/JetSurF2.0.

[24] Reitzer BJ, Lamb GG. Preflame Oxidation and Detonation of Cyclopentane and 2,2,4-Trimethylpentane. Ind Eng Chem 1955;47:1239-42. doi:10.1021/ie50546a053.

[25] Yang Y, Boehman AL. Experimental study of cyclohexane and methylcyclohexane oxidation at low to intermediate temperature in a motored engine. Proc Combust Inst 2009;32:419-26. doi:10.1016/j.proci.2008.06.162.

[26] Yang Y, Boehman AL. Oxidation chemistry of cyclic hydrocarbons in a motored engine: Methylcyclopentane, tetralin, and decalin. Combust Flame 2010;157:495-505. doi:10.1016/j.combustflame.2009.08.011.

[27] Guillen DP. The Autoignition of Cyclopentane in an Ignition Quality Tester. JOM 2012;64:985-9. doi:10.1007/s11837-012-0369-2.

[28] Al Rashidi MJ, Mármol JC, Banyon C, Sajid MB, Mehl M, Pitz WJ, et al. Cyclopentane combustion. Part II. Ignition delay measurements and mechanism validation. Combust Flame 2017;183:372-85.

doi:10.1016/j.combustflame.2017.05.017.

[29] Dec JE, Yang Y. Boosted HCCl for High Power without Engine Knock and with Ultra-Low NOx Emissions - using Conventional Gasoline. SAE Int J Engines 2010;3:2010-01-1086. doi:10.4271/2010-01-1086.

[30] Al Rashidi MJ, Mehl M, Pitz WJ, Mohamed S, Sarathy SM. Cyclopentane combustion chemistry. Part I: Mechanism development and computational kinetics. Combust Flame 2017;183:358-71. doi:10.1016/j.combustflame.2017.05.018.

[31] Goldsborough SS, Johnson MV, Banyon C, Pitz WJ, McNenly MJ. Experimental and modeling study of fuel interactions with an alkyl nitrate cetane enhancer, 2-ethyl-hexyl nitrate. Proc Combust Inst 2015;35:571-9. doi:10.1016/j.proci.2014.06.048.

[32] Voinov AN, Skorodelov DI, Sokolov FP. No Title. Kinet i Katal 1964;5:388-98.

[33] Affleck WS, Thomas A. An opposed piston rapid compression machine for preflame reaction studies. Arch Proc Inst Mech Eng 1847-1982 (Vols 1-196) 1968;183:365-87. doi:10.1243/PIME_PROC_1968_183_034_02.

[34] Elsworth JE, Haskell WW, Read IA. Non-uniform ignition processes in rapid-compression machines. Combust Flame 1969;13:437-8. doi:10.1016/0010-2180(69)90115-1.

[35] Haskell WW. Fuel Ignition in a Rapid Compression Machine: Sensitivity to Flame Ignition by Particles, 1970. doi:10.4271/700059.

[36] Sung C-J, Curran HJ. Using rapid compression machines for chemical kinetics studies. Prog Energy Combust Sci 2014;44:1-18. doi:10.1016/j.pecs.2014.04.001.

[37] Burgess DR. Thermochemical Data. In: Linstrom PJ, Mallard WG, editors. NIST Chem. WebBook, NIST Stand. Ref. Database Number 69, Gaithersburg: National Institute of Standards and Technology; 2015.

[38] Ebrahimi R. Effect of specific heat ratio on heat release analysis in a spark ignition engine. Sci Iran 2011;18:1231-6. doi:10.1016/j.scient.2011.11.002.

[39] Heywood JB. Internal Combustion Engine Fundamentals. 1st ed. McGraw-Hill Education; 1998.

[40] Goldsborough SS, Santner J, Kang D, Fridlyand A, Rockstroh T, Jespersen MC. Heat release analysis for rapid compression machines: Challenges and opportunities. Proc Combust Inst 2018. doi:10.1016/j.proci.2018.05.128.

[41] Weber BW, Sung C-J, Renfro MW. On the uncertainty of temperature estimation in a rapid compression machine. Combust Flame 2015;162:2518-28. doi:10.1016/j.combustflame.2015.03.001.

[42] Neuman J, Allen CM. The Influence of Non-Uniform Initial Conditions on Temperature Field Development in Rapid 
Compression Machine Experiments. 52nd Aerosp. Sci. Meet., Reston, Virginia: American Institute of Aeronautics and Astronautics; 2014. doi:10.2514/6.2014-0128.

[43] Mittal G, Raju MP, Sung C-J. CFD modeling of two-stage ignition in a rapid compression machine: Assessment of zero-dimensional approach. Combust Flame 2010;157:1316-24. doi:10.1016/j.combustflame.2010.02.019.

[44] Goldsborough SS, Mittal G, Banyon C. Methodology to account for multi-stage ignition phenomena during simulations of RCM experiments. Proc Combust Inst 2013;34:685-93. doi:10.1016/j.proci.2012.05.094.

[45] Goteng GL, Nettyam N, Sarathy SM. CloudFlame: Cyberinfrastructure for Combustion Research. 2013 Int Conf Inf Sci Cloud Comput Companion 2013:294-9. doi:10.1109/ISCC-C.2013.57.

[46] Goteng GL, Speight M, Nettyam N, Farooq A, Frenklach M, Sarathy SM. A hybrid cloud system for combustion kinetics simulation. 23rd Int. Symp. Gas Kinet. Relat. Phenomena, Hungary, 2014.

[47] Reyno-Chiasson Z, Nettyam N, Goteng GL, Speight M, Lee BJ, Baskaran S, et al. CloudFlame and PrIMe: accelerating combustion research in the cloud. 9th Int. Conf. Chem. Kinet. Ghent, Belgium, 2015.

[48] Goldsborough SS, Hochgreb S, Vanhove G, Wooldridge MS, Curran HJ, Sung C-J. Advances in rapid compression machine studies of low- and intermediate-temperature autoignition phenomena. Prog Energy Combust Sci 2017;63:1-78. doi:10.1016/j.pecs.2017.05.002.

[49] Tsang W. Thermal decomposition of cyclopentane and related compounds. Int J Chem Kinet 1978;10:599-617. doi:10.1002/kin.550100607.

[50] Sivaramakrishnan R, Michael JV. Shock tube measurements of high temperature rate constants for $\mathrm{OH}$ with cycloalkanes and methylcycloalkanes. Combust Flame 2009;156:1126-34.

doi:10.1016/j.combustflame.2008.10.010.

[51] Benson SW. Thermochemical kinetics: methods for the estimation of thermochemical data and rate parameters. New York: Wiley; 1976.

[52] Ritter ER, Bozzelli JW. THERM: Thermodynamic property estimation for gas phase radicals and molecules. Int J Chem Kinet 1991;23:767-78. doi:10.1002/kin.550230903.

[53] Villano SM, Huynh LK, Carstensen H-H, Dean AM. High-Pressure Rate Rules for Alkyl + O2 Reactions. 1. The Dissociation, Concerted Elimination, and Isomerization Channels of the Alkyl Peroxy Radical. J Phys Chem A 2011;115:13425-42. doi:10.1021/jp2079204.

[54] Villano SM, Huynh LK, Carstensen H-H, Dean AM. High-Pressure Rate Rules for Alkyl + O2 Reactions. 2. The Isomerization, Cyclic Ether Formation, and $\beta$-Scission Reactions of Hydroperoxy Alkyl Radicals. J Phys Chem A 2012;116:5068-89. doi:10.1021/jp3023887.

[55] Miyoshi A. Systematic Computational Study on the Unimolecular Reactions of Alkylperoxy (RO2), Hydroperoxyalkyl (QOOH), and Hydroperoxyalkylperoxy (O2QOOH) Radicals. J Phys Chem A 2011;115:3301-25. doi:10.1021/jp112152n.

[56] Goldsmith CF, Klippenstein SJ, Green WH. Theoretical rate coefficients for allyl+HO2 and allyloxy decomposition. Proc Combust Inst 2011;33:273-82. doi:10.1016/j.proci.2010.05.054.

[57] Sharma S, Raman S, Green WH. Intramolecular Hydrogen Migration in Alkylperoxy and Hydroperoxyalkylperoxy Radicals: Accurate Treatment of Hindered Rotors. J Phys Chem A 2010;114:5689-701. doi:10.1021/jp9098792.

[58] Jalan A, Alecu IM, Meana-Pañeda R, Aguilera-Iparraguirre J, Yang KR, Merchant SS, et al. New Pathways for Formation of Acids and Carbonyl Products in Low-Temperature Oxidation: The Korcek Decomposition of $\gamma$ Ketohydroperoxides. J Am Chem Soc 2013;135:11100-14. doi:10.1021/ja4034439.

[59] Sarathy SM, Westbrook CK, Mehl M, Pitz WJ, Togbe C, Dagaut P, et al. Comprehensive chemical kinetic modeling of the oxidation of 2-methylalkanes from C7 to C20. Combust Flame 2011;158:2338-57. doi:10.1016/j.combustflame.2011.05.007.

[60] Harding LB, Georgievskii Y, Klippenstein SJ. Predictive Theory for Hydrogen Atom-Hydrocarbon Radical Association Kinetics. J Phys Chem A 2005;109:4646-56. doi:10.1021/jp0508608.

[61] Tsang W, Walker JA, Manion JA. The decomposition of normal hexyl radicals. Proc Combust Inst 2007;31 I:141-8. doi:10.1016/j.proci.2006.07.069.

[62] Sjöberg M, Dec JE, Hwang W. Thermodynamic and Chemical Effects of EGR and Its Constituents on HCCI Autoignition, 2007. doi:10.4271/2007-01-0207.

[63] Miller JA, Pilling MJ, Troe J. Unravelling combustion mechanisms through a quantitative understanding of elementary reactions. Proc Combust Inst 2005;30:43-88. doi:10.1016/j.proci.2004.08.281.

[64] Wagnon SW, Wooldridge MS. Effects of buffer gas composition on autoignition. Combust Flame 2014;161:898-907. doi:10.1016/j.combustflame.2013.09.022.

[65] S. Scott G. A chemical kinetically based ignition delay correlation for iso-octane covering a wide range of conditions including the NTC region. Combust Flame 2009;156:1248-62. doi:10.1016/j.combustflame.2009.01.018.

[66] Merchant SS, Goldsmith CF, Vandeputte AG, Burke MP, Klippenstein SJ, Green WH. Understanding low-temperature 
first-stage ignition delay: Propane. Combust Flame 2015,162:3658-73. doi.10.1016/j.combustflame.2015.07.005. Mansfield AB, Wooldridge MS. High-pressure low-temperature ignition behavior of syngas mixtures. Combust Flame 2014;161:2242-51. doi:10.1016/j.combustflame.2014.03.001.

[68] Fieweger K, Blumenthal R, Adomeit G. Self-ignition of S.I. engine model fuels: A shock tube investigation at high pressure. Combust Flame 1997;109:599-619. doi:10.1016/S0010-2180(97)00049-7.

[69] Mittal G, Chomier M. Interpretation of experimental data from rapid compression machines without creviced pistons. Combust Flame 2014;161:75-83. doi:10.1016/j.combustflame.2013.08.020.

[70] Yoo CS, Luo Z, Lu T, Kim H, Chen JH. A DNS study of ignition characteristics of a lean iso-octane/air mixture under $\mathrm{HCCl}$ and SACl conditions. Proc Combust Inst 2013;34:2985-93. doi:10.1016/j.proci.2012.05.019.

[71] Mittal G, Sung CJ. Aerodynamics inside a rapid compression machine. Combust Flame 2006;145:160-80. doi:10.1016/j.combustflame.2005.10.019.

[72] DESGROUX P, MINETTI R, SOCHET LR. Temperature Distribution Induced by Pre-Ignition Reactions in a Rapid Compression Machine. Combust Sci Technol 1996;113:193-203. doi:10.1080/00102209608935494.

[73] Borisov AA. On the origin of exothermic centers in gaseous mixtures. Acta Astronaut 1974;1:909-20. doi:10.1016/0094-5765(74)90059-9.

[74] Randazzo JB, Annesley CJ, Bell K, Tranter RS. A shock tube laser schlieren study of cyclopentane pyrolysis. Proc Combust Inst 2016. doi:10.1016/j.proci.2016.05.038.

[75] Fridlyand A, Lynch PT, Tranter RS, Brezinsky K. Single Pulse Shock Tube Study of Allyl Radical Recombination. J Phys Chem A 2013;117:4762-76. doi:10.1021/jp402391n.

[76] Luong MB, Sankaran R, Yu GH, Chung SH, Yoo CS. On the effect of injection timing on the ignition of lean PRF/air/EGR mixtures under direct dual fuel stratification conditions. Combust Flame 2017;183:309-21. doi:10.1016/j.combustflame.2017.05.023.

[77] Meyer JW, Oppenheim AK. On the shock-induced ignition of explosive gases. Symp Combust 1971;13:1153-64. doi:10.1016/S0082-0784(71)80112-1.

[78] Walton SM, He X, Zigler BT, Wooldridge MS. An experimental investigation of the ignition properties of hydrogen and carbon monoxide mixtures for syngas turbine applications. Proc Combust Inst 2007;31:3147-54. doi:10.1016/j.proci.2006.08.059.

[79] Lee C, Vranckx S, Heufer KA, Khomik S V., Uygun Y, Olivier H, et al. On the Chemical Kinetics of Ethanol Oxidation: Shock Tube, Rapid Compression Machine and Detailed Modeling Study. Zeitschrift Für Phys Chemie 2012;226:1-28. doi:10.1524/zpch.2012.0185.

[80] Mittal G, Sung C-J. Autoignition of toluene and benzene at elevated pressures in a rapid compression machine. Combust Flame 2007;150:355-68. doi:10.1016/j.combustflame.2007.04.014.

[81] Mani Sarathy S, Park S, Weber BW, Wang W, Veloo PS, Davis AC, et al. A comprehensive experimental and modeling study of iso-pentanol combustion. Combust Flame 2013;160:2712-28. doi:10.1016/j.combustflame.2013.06.022.

[82] Zádor J, Zsély IG, Turányi T, Ratto M, Tarantola S, Saltelli A. Local and Global Uncertainty Analyses of a Methane Flame Model. J Phys Chem A 2005;109:9795-807. doi:10.1021/jp053270i.

[83] Metcalfe WK, Burke SM, Ahmed SS, Curran HJ. A Hierarchical and Comparative Kinetic Modeling Study of C1 - C2 Hydrocarbon and Oxygenated Fuels. Int J Chem Kinet 2013;45:638-75. doi:10.1002/kin.20802.

[84] Bourgeois N, Goldsborough SS, Jeanmart H, Contino F. CFD simulations of Rapid Compression Machines using detailed chemistry: Evaluation of the 'crevice containment' concept. Combust Flame 2018;189:225-39.

doi:10.1016/j.combustflame.2017.10.033.

\subsection{Supplementary Material}

Table S1 - ignition times for CPT tests.

Table S2 - ignition times for MCP tests.

Table S3 - ignition times for ECP tests.

Derived volume histories based on non-reactive tests.

Chemical kinetic model and associated thermochemistry. 